\title{
Tropospheric ozone from IASI: comparison of different inversion algorithms and validation with ozone sondes in the northern middle latitudes
}

\author{
C. Keim ${ }^{1, *}$, M. Eremenko ${ }^{1}$, J. Orphal ${ }^{1}$, G. Dufour ${ }^{1}$, J.-M. Flaud ${ }^{1}$, M. Höpfner ${ }^{2}$, A. Boynard ${ }^{3}$, C. Clerbaux ${ }^{3}$, S. Payan ${ }^{4}$, \\ P.-F. Coheur ${ }^{5}$, D. Hurtmans ${ }^{5}$, H. Claude ${ }^{6}$, H. Dier ${ }^{7}$, B. Johnson ${ }^{8}$, H. Kelder ${ }^{9}$, R. Kivi ${ }^{10}$, T. Koide ${ }^{11}$, \\ M. López Bartolomé ${ }^{12}$, K. Lambkin ${ }^{13}$, D. Moore ${ }^{14}$, F. J. Schmidlin ${ }^{15}$, and R. Stübi ${ }^{16}$ \\ ${ }^{1}$ Laboratoire Interuniversitaire des Systèmes Atmosphériques (LISA), CNRS/ Univ. Paris 12 et 7, Créteil, France \\ ${ }^{2}$ Institut für Meteorologie und Klimaforschung, Forschungszentrum Karlsruhe, Germany \\ ${ }^{3}$ UPMC Univ Paris 06, CNRS UMR8190, LATMOS/IPSL, Paris, France \\ ${ }^{4}$ Laboratoire de Physique Moléculaire pour l'Atmosphére et l'Astrophysique, Université Pierre et Marie Curie-Paris 6, \\ Paris, France \\ ${ }^{5}$ Spectroscopie de l'Atmosphère, Service de Chimie Quantique et de Photophysique, Université Libre de Bruxelles (U.L.B.), \\ Brussels, Belgium \\ ${ }^{6}$ Meteorological Observatory Hohenpeißenberg, DWD, Hohenpeißenberg, Germany \\ ${ }^{7}$ Richard-Aßmann-Observatorium, DWD, Lindenberg, Germany \\ ${ }^{8} \mathrm{NOAA} / \mathrm{ESRL}$, Boulder, CO, USA \\ ${ }^{9}$ Department of Applied Physics, Eindhoven University of Technology, Eindhoven, The Netherlands \\ ${ }^{10}$ Finnish Meteorological Institute, Sodankylä, Finland \\ ${ }^{11}$ Ozone Layer Monitoring Office, Japan Meteorological Agency, Tokyo, 100-8122 Japan \\ ${ }^{12}$ Agencia Estatal de Meteorología (AEMET), Madrid, Spain \\ ${ }^{13}$ Met Éireann, The Irish Meteorological Service, Valentia Observatory, Cahirciveen, Kerry, Ireland \\ ${ }^{14}$ Met Office, Exeter, UK \\ ${ }^{15}$ NASA Goddard Space Flight Center, Wallops Flight Facility, Wallops Island, USA \\ ${ }^{16}$ Federal Office of Meteorology and Climatology, MeteoSwiss, Aerological Station, Payerne, Switzerland \\ *now at: Astrium $\mathrm{GmbH}$, Germany
}

Received: 24 February 2009 - Published in Atmos. Chem. Phys. Discuss.: 8 May 2009

Revised: 6 November 2009 - Accepted: 26 November 2009 - Published: 15 December 2009

\begin{abstract}
This paper presents a first statistical validation of tropospheric ozone products derived from measurements of the IASI satellite instrument. Since the end of 2006, IASI (Infrared Atmospheric Sounding Interferometer) aboard the polar orbiter Metop-A measures infrared spectra of the Earth's atmosphere in nadir geometry. This validation covers the northern mid-latitudes and the period from July 2007 to August 2008. Retrieval results from four different sources are presented: three are from scientific products (LATMOS, LISA, LPMAA) and the fourth one is the pre-operational product distributed by EUMETSAT (version
\end{abstract}

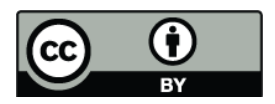

Correspondence to: M. Eremenko (maxim.eremenko@lisa.univ-paris12.fr)
4.2). The different products are derived from different algorithms with different approaches. The difference and their implications for the retrieved products are discussed. In order to evaluate the quality and the performance of each product, comparisons with the vertical ozone concentration profiles measured by balloon sondes are performed and lead to estimates of the systematic and random errors in the IASI ozone products (profiles and partial columns). A first comparison is performed on the given profiles; a second comparison takes into account the altitude dependent sensitivity of the retrievals. Tropospheric columnar amounts are compared to the sonde for a lower tropospheric column (surface to about $6 \mathrm{~km}$ ) and a "total" tropospheric column (surface to about $11 \mathrm{~km}$ ). On average both tropospheric columns have small biases for the scientific products, less than 2 Dobson

Published by Copernicus Publications on behalf of the European Geosciences Union. 
Units (DU) for the lower troposphere and less than $1 \mathrm{DU}$ for the total troposphere. The comparison of the still preoperational EUMETSAT columns shows higher mean differences of about 5 DU.

\section{Introduction}

Ozone is a key species in the photochemistry of the troposphere and is a pollutant with significant impact on health and agriculture (Seinfeld and Pandis, 1998). It is also an important greenhouse gas with strong radiative forcing in the upper troposphere (Fishman et al., 1979). Monitoring of tropospheric ozone is extremely important for the understanding and quantification of air pollution (including the possibility to distinguish between local sources and long-range transport of pollution) and to predict and engineer air quality at the local and regional scales. Ozone concentrations are currently measured at the surface level using national operational networks, furthermore vertical concentration profiles are measured at selected sites using meteorological balloon sondes. In this context, satellite observations in nadir geometry are very interesting because of their high spatial coverage, but such observations are limited in terms of temporal coverage (typically 1-2 measurements per day for a given location), and they are particularly difficult for tropospheric ozone because the stratospheric ozone layer contributes for the main part of the ozone total column. Vertical resolution is therefore a crucial issue for satellite measurements of tropospheric ozone.

The first satellite measurements of tropospheric ozone have been obtained from instruments measuring solar reflected and backscattered light using residual techniques (Fishman et al., 2003) but have limitations especially in midand high latitudes. More recently, using atmospheric spectra in the ultraviolet-visible from instruments like GOME (Global Ozone Monitoring Experiment, Liu et al., 2005), tropospheric ozone columns have been obtained but again with little information in the mid- and high latitudes. It has been demonstrated (Turquety et al., 2002; Coheur et al., 2005) that atmospheric spectra in the thermal infrared can provide accurate measurements of tropospheric ozone, with the additional advantage that measurements are also possible during the night. In particular, the TES (Tropospheric Emission Spectrometer) instrument aboard the EOS-Aura satellite has provided measurements of tropospheric ozone (Worden et al., 2007) with first applications to air quality modelling (Jones et al., 2008) and climate (through an estimate of its radiative forcing) (Worden et al., 2008). More recently, the European IASI (Infrared Atmospheric Sounding Interferometer) instrument aboard the Metop-A satellite (launched in late 2006) has started with operational measurements in summer 2007. In contrast to TES, IASI has a very large spatial coverage and is therefore well suited for measurements of tropospheric ozone with an air quality focus. A first study of tropospheric ozone during the heat wave over Europe in summer 2007 has been published very recently (Eremenko et al., 2008), demonstrating the great potential of IASI measurements for air quality applications.

In the paper, we present the first detailed comparison of tropospheric ozone products, obtained using different inversion algorithms and methods, for the same IASI measurement dataset, as well as the validation of these products using vertical ozone concentration profiles obtained from balloon sondes. This study is in particular important to identify possible systematic errors or biases in the available tropospheric ozone products.

The paper is organised as follows: first, after a short introduction focusing on the IASI instrument, the different retrieval methods and inversion algorithms are presented and discussed. The second part describes the in situ measurements and the coincidence criteria used for the validations. In the third part, the methods and results of the different comparisons are shown and discussed.

\section{The IASI instruments on Metop}

IASI (Infrared Atmospheric Sounding Interferometer, Clerbaux et al., 2007) are nadir viewing Fourier-transform spectrometers designed for operation on the meteorological Metop satellites (ESA/EUMETSAT). The first instrument was launched in orbit aboard the satellite Metop-A on 19 October 2006, and started operational measurements in June 2007. Two other IASI instruments will be launched in 2010 and 2015, respectively, with a nominal lifetime of 5 years. IASI is a Michelson-type Fourier-transform spectrometer with a maximal optical path difference of $2 \mathrm{~cm}$ and a spectral range from $645 \mathrm{~cm}^{-1}$ to $2760 \mathrm{~cm}^{-1}$. After apodisation with a Gaussian function, a spectral resolution of $0.5 \mathrm{~cm}^{-1}$ is obtained. The instrument scans the Earth's surface perpendicular to the satellite's flight track with 15 individual views on each side of the track. At the nadir point, the size of one view is $50 \times 50 \mathrm{~km}$. It consists of 4 individual ground pixels with $12 \mathrm{~km}$ diameter each (at the nadir point), achieved by using 4 detector pixels for each IASI channel. The maximum scan angle of 48.3 degrees from nadir equals a distance of $1100 \mathrm{~km}$ from the centre of the ground pixel to the flight track projection (sub-satellite point).

The polar sun-synchronous orbit of Metop crosses the equator at two fixed local solar times: 09:30 a.m. (descending) and 09:30 p.m. (ascending). The distance between two successive overpasses is 25 degrees longitude, this equals $2800 \mathrm{~km}$ at the equator and decreases towards the poles. For latitudes higher than 45 degrees, the scanning ranges of two successive overpasses overlap. This means that a location like Paris $\left(49^{\circ} \mathrm{N}\right)$ is covered by at least 2 overpasses per day. Depending on where these overlap regions are located, up to 4 overpasses can occur. The EUMETSAT products of IASI 
distributed by EUMETCast are surface temperature, cloud properties, vertical profiles of temperature and humidity, and partial columns of ozone and several other trace gases.

\section{The different retrieval approaches}

The measured spectra of IASI (or any other spectrometer) can be simulated by the use of an atmospheric radiative transfer model. Based on the radiative transfer equation, the spectral radiances that are measured by the instrument are calculated with such a model taking into account the atmospheric and instrumental parameters. A comparison of atmospheric radiances calculated with different radiative transfer models has been made previously by Tjemkes et al. (2003) with the result of a generally good agreement in the spectral range from $800-2600 \mathrm{~cm}^{-1}$. The agreement of spectra calculated with radiative transfer models compared to the measured spectra depends not only on the exact implementation of the basic equations in the algorithms, but also on the atmospheric and instrumental parameters that are used in these calculations.

To obtain the vertical ozone profile from a given atmospheric spectrum, the atmospheric radiative transfer equation has to be inverted. There are two principal numerical approaches to perform this inversion.

The first one is a full numerical method: the atmospheric profile predicted by the radiative transfer model is iteratively adapted to minimise the (root mean squared) difference between the calculated and measured spectra. The minimisation may be constraint by the smoothness of the profile (Tikhonov-Philips regularisation; Tikhonov, 1963; Phillips, 1962), by its closeness to a given a priori profile (optimal estimation; Rodgers, 2000), or by a combination of both constraints. For each iteration step, the full radiative transfer has to be calculated. This approach is time-consuming and does not allow performing the inversion of IASI spectra in real time (120 spectra in $8 \mathrm{~s}$ ) for the operational retrieval.

The second approach consists in a neural network: the network is trained by spectra calculated from various different atmospheric profiles, representative of the most common atmospheric conditions but also covering less probable cases, with the aim of reproducing the columnar amounts. The inversion of a given spectrum with the neural network is a nonlinear interpolation of the training data set. Extreme atmospheric situations which were not covered by the training dataset may lead to wrong columns, since the network performs a nonlinear extrapolation. This problem is counterbalanced by the high calculation speed of this method. For this reason, the neural network approach was chosen for the operational data processing at EUMETSAT (Turquety, 2004).

Three research groups namely LATMOS, LISA and LPMAA have provided retrieved data sets of IASI products (profiles and partial columns) at the location of the ozone sonde stations. These kinds of products are usually referred as scientific products because they are usually more precise due to less constraint on the delivery time delay. The operational product delivered by EUMETSAT is also included in the current study. In the following subsections we describe briefly the different retrieval approaches that were used in the intercomparison of the ozone products of this study.

\subsection{Retrieval at LATMOS}

At LATMOS (Laboratoire Atmosphères, Milieux, Observations Spatiales, France), trace gases concentrations are retrieved from the IASI spectra using different algorithms (Clerbaux et al., 2009). For the ozone profiles, the ATMOSPHIT software (Clerbaux et al., 2005; Coheur et al., 2005) is used. It contains ray tracing for various geometries, a line-by-line radiative transfer model and an inversion scheme that relies on the Optimal Estimation (OE) theory (Rodgers, 2000). A synthetic spectrum is computed in ATMOSPHIT using either the line parameters or the absorption cross sections for heavier molecules, for which the line parameters are not available. Both kind of parameters are taken from the HITRAN 2004 (Rothman et al., 2005) database. The OE retrieval approach relies on a priori assumptions that determine the linearisation point about which a retrieval is constrained. This is known as a priori information, composed of a mean state and an a priori covariance matrix, which has to represent the best statistical knowledge of the state prior to the measurements.

The ozone a priori profile and the covariance matrix are derived from a set of radiosonde measurements from all over the globe (available data during the period 2004-2008) connected to the UGAMP monthly climatology ( $\mathrm{Li}$ and Shine, 1995 ) above $30-35 \mathrm{~km}$. It is thus representative of the global and annual ozone variability.

A full description of the retrieval set-up is provided in Boynard et al. (2009). Temperature profiles used in the inversion process are bi-linear interpolation of ECMWF temperature fields on the IASI observation pixels.

LATMOS retrievals cover the entire period, but have not been performed for all stations (see Table 2).

\subsection{Retrieval at LISA}

The retrieval of ozone profiles from IASI spectra at LISA (Laboratoire Interuniversitaire des Systèmes Atmosphériques, France) is performed with the radiative transfer model KOPRA (Karlsruhe Optimised and Precise Radiative transfer Algorithm, Stiller et al., 2000) and its numerical inversion module KOPRAFIT. KOPRA was developed for the retrieval of spectra of the MIPAS instrument aboard ENVISAT (Fischer et al., 2008). Recently it has also been applied to the analysis of spectra measured with IASI on Metop (Eremenko et al., 2008). The atmospheric profiles are calculated on a vertical grid of $1 \mathrm{~km}$ below $40 \mathrm{~km}$ and $2 \mathrm{~km}$ above. To achieve maximal information content in the troposphere, 
Table 1. Summary of the properties of the retrievals used by the three teams

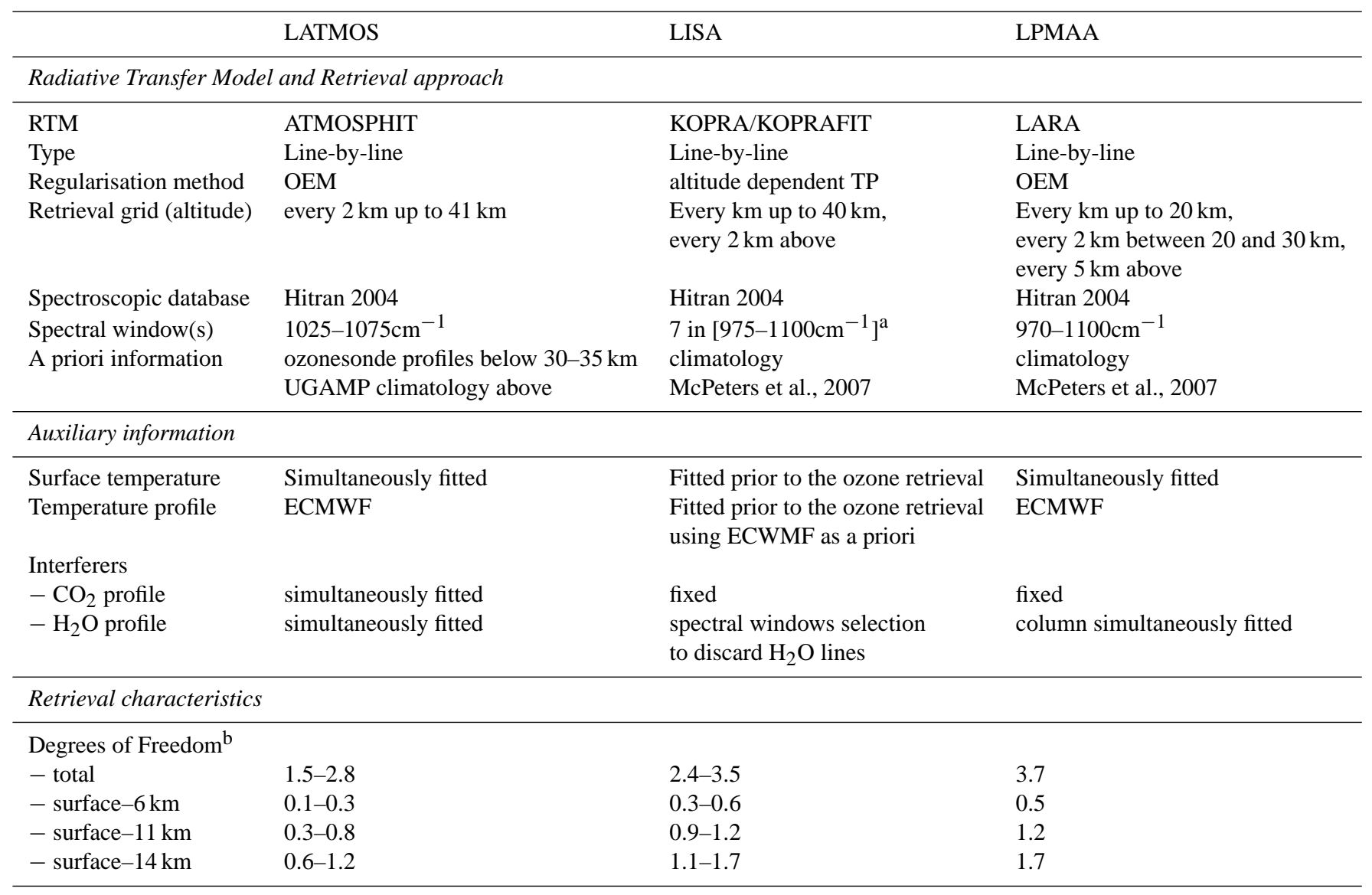

a only the six strong water lines are discarded.

$\mathrm{b}$ The ranges provided for the DOFs are derived from the two typical cases (cold and warm surface temperature) displayed in Fig. 1, for LISA and LATMOS. For LPMAA, the DOFs are for the warm surface case.

the regularisation was adapted to the atmospheric weighting function and the IASI viewing geometry. Here, a combination of zero, first and second order Thikonov constraints with altitude-dependent coefficients similar to Kulawik et al. (2006) was employed. These coefficients were optimised using a simplex method (Nelder and Mead, 1965) to both maximise the Degrees of Freedom (DOF) of the retrieval (Steck, 2006) in the troposphere and to minimise the total error of the retrieved profile.

The analysis of IASI data at LISA is performed in three steps (with ozone being the last step): the first step is the retrieval of the effective surface temperature. Note that the radiance reaching the top of the atmosphere is not necessarily from the surface, but may be influenced by water vapour and dust or aerosol in the boundary layer. To estimate the background radiance, a blackbody with emissivity equal to 1 was assumed and its temperature was retrieved at $11 \mu \mathrm{m}$ close to the ozone band used in the retrieval. In the second step, the atmospheric temperature profile is retrieved using the $\mathrm{CO}_{2}$ band around $15 \mu \mathrm{m}$ and the ECMWF profiles as a priori. Finally, in the third step, the ozone profile retrieval is performed in the $975-1100 \mathrm{~cm}^{-1}$ spectral region using seven microwindows that exclude strong water lines. For all gases, the spectroscopic parameters in the HITRAN 2004 database were used. The a priori information was constructed using the climatology of McPeters et al. (2007).

Before all retrievals, the IASI spectra are filtered for cloud contamination, and only spectra for clear sky conditions are used in the intercomparison data set. After their retrieval, the ozone profiles are screened for nonphysical shapes.

For more details on the retrieval, especially on regularisation and error estimation, the reader should refer to Eremenko et al. (2008).

LISA retrievals cover the entire period and all stations listed in Table 2. 


\subsection{Retrieval at LPMAA}

LPMAA (Laboratoire de Physique Moléculaire pour l'Atmosphère et l'Astrophysique, France) Atmospheric Retrieval Algorithm (LARA) which has been developed over the years is a home made radiative transfer model associated with an inversion algorithm. The corresponding software has been used to analyse atmospheric spectra recorded using, ground-based, balloon- or satellite-borne experiments, both in absorption or emission mode, and for the limb or nadir geometry. LARA has been used to perform simulations of atmospheric spectra for the preparation of satellite experiments and for assessing the information content expected from instruments with different characteristics.

The algorithm LARA allows the simultaneous inversion of spectra in several windows for the joint retrieval of vertical profiles (or slant column densities) of various species (Payan et al., 1998). Surface temperature and emissivity, and if needed instrumental line shape or instrumental spectral shift may be fitted together with the species.

The LPMAA retrieval algorithm includes an accurate lineby-line radiative transfer model and an efficient minimisation algorithm of the Levenberg-Marquardt type. The optimal estimation method is used for the retrieval process. The full error covariance matrix is calculated within the retrieval process. The forward model (i.e. the radiative transfer model) uses molecular parameters which are mainly extracted from the HITRAN 2004 database. Individual line shapes are calculated with a Voigt profile based on the Lorentzian parameters listed in the spectroscopic database and the line shifting coefficient can be used when non-zero in HITRAN 2004. The calculation is accounting for the water vapour continuum (Clough et al., 2005) as well as water vapour self-broadening. The reflected downward flux and the reflected or diffused sunlight are modelled.

For the present work, the algorithm was tailored to the specificities of the IASI spectra and geometry. Surface emissivity has been fixed to one, while surface temperature has been retrieved together with the ozone profile.

LPMAA retrievals cover the summer (JJA) 2007 and two European mid-latitude stations (see Table 2).

\subsection{Retrieval at EUMETSAT}

The neural network used for ozone at EUMETSAT is of feedforward type with two hidden layers. From selected channels in the input layer it derives 4 partial ozone columns in the output layer. The partial columns span 1050-478.54 hPa, 1050 $222.94 \mathrm{hPa}, 1050-132.49 \mathrm{hPa}$, and $1050-0.005 \mathrm{hPa}$, respectively. The two first columns cover only the troposphere, whereas the last one is the total column. We refer to Turquety (2004) and EUMETSAT (2004) for more details.

The training data set is the essential core for the resulting quality of the retrieval. The learning base was made of a collection of atmospheric state vector and their associated synthetic spectra computed with the forward model RTIASI (Matricardi and Saunders, 2007). The various atmospheric cases were sampled in the Chevallier database (Chevallier, 2001), to which different scan angles and solar elevations were randomly associated in order to equally cover all expected geographical and geometrical combinations.

The target accuracy for the partial columns was set to $28 \%$, $15 \%, 9 \%$, and $2.5 \%$, respectively for cloud-free conditions. The algorithm is able to treat optically thin clouds, nevertheless concerned columns are flagged. We decided to exclude columns flagged as (partially) cloudy in the comparison, to avoid the question, whether differences in the ozone columns derive from the ozone or the cloud treatment.

Ozone columns are available from 26 February 2008 ongoing, but only for pixels with odd numbers.

Until the morning overpass on June 10, 2008, there was an error in the EumetCast transmitted data. The scaling of the ozone columns was wrong by exactly a factor of ten. We corrected this before the comparison.

Until 11 August 2008, the retrieval version was v4.2, the successive version $\mathrm{v} 4.3$ was trained with a new data set (August et al., 2008). We limited therefore the comparison on version v4.2. Until now, for the validation of $\mathrm{v} 4.3$, there are not enough sonde measurements available.

\subsection{Discussion on the different methods}

The neural network approach and the numerical approach are intrinsically different. The neural network acts as a superinterpolator within the training dataset. The retrieval is then more or less the selection of the best matching profile from the training dataset and is meaningful only within the range of this dataset. The numerical approaches are based on constrained least square fits (ill-posed problem) and give satisfactory results if the solution is not too far from the a priori. The choice of the constraint and the a priori information are key factors in the final quality and performances of the method, independently of the sensitivity and the noise of the instrument and the measurement type. In the current paper, two different types of constraint are used by the different groups. Table 1 summarises the characteristics and the conditions of the different retrieval approaches. The first approach is the well known optimal estimation method used by LATMOS and LPMAA. In this method, the constraint is based on the best a priori knowledge of the state of the atmosphere before the observations. The strength of the constraint is determined by the a priori known variability of the ozone profiles in our specific case. This is mainly the values of the ozone concentration at the altitudes of the retrieval grid that are constrained. The a priori profile and its associated covariance matrix are usually derived from climatologies (Table 1). This set-up of the constraint is the major difference between the retrievals at LATMOS and LPMAA. The second approach, used at LISA, is based on an altitude-dependent Tikhonov-Philipps regularisation. The constraint matrix is a 


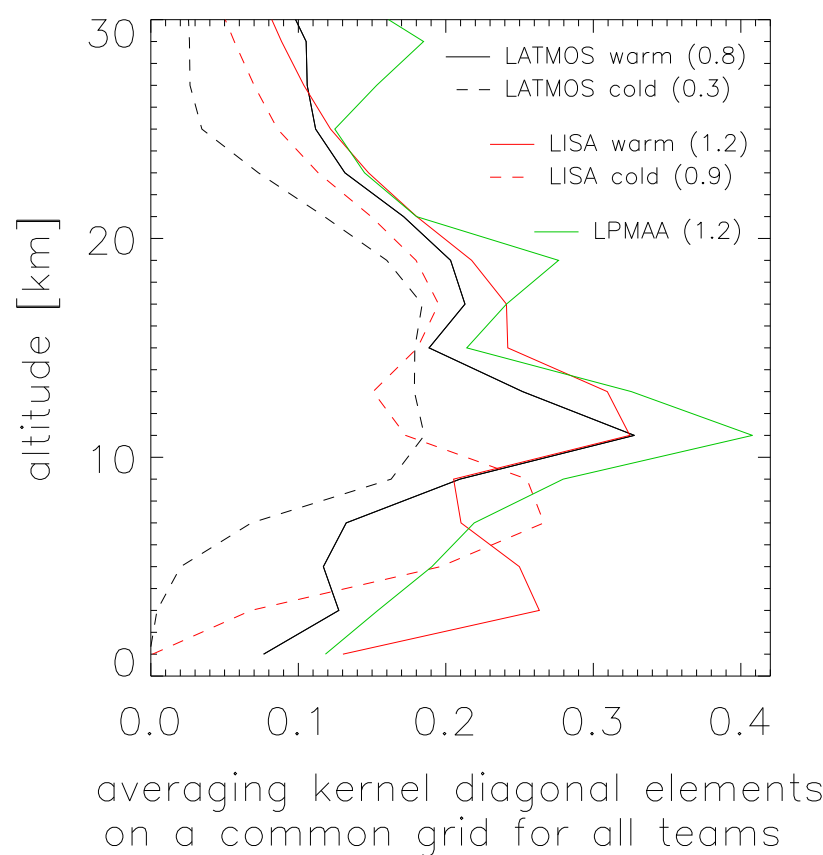

Fig. 1. Comparison of the diagonals of the averaging kernel matrix of different profile retrieval approaches on a common grid (see Eq. 1). As examples we chose a cold case (surface temperature about $262 \mathrm{~K}$ ) and a warm case $(297 \mathrm{~K})$ around the station in Lindenberg, Germany. For the retrieval at LPMAA, we present the mean averaging kernels for the summer 2007 period, which correspond to the warm case. In parentheses we give the DOF for the column from the surface up to $11 \mathrm{~km}$.

combination of the zero, first and second derivatives combined with optimised altitude-dependent coefficients. The strength of the constraint, through these coefficients, is defined in order to keep a physical sense to the solution with the best compromise between optimised degrees of freedom and minimised errors. The shape of the profile is also constrained with this method.

The averaging kernels (i.e. the rows of the averaging kernel matrix A) characterise the sensitivity of the retrieved profiles on the true state of the atmosphere. The choice of the retrieval approach can slightly modify the sensitivity, but not the general characteristics of the inversion and of the averaging kernel matrix that are driven by the instrumental noise and the observation geometry. In Fig. 1 we show the diagonals of typical averaging kernel matrices for the different retrieval methods involved in this work. To make the values comparable, we transformed the averaging kernel matrix of the LISA and LPMAA retrievals onto the LATMOS-altitudegrid, using Eq. (1) (von Clarmann and Grabowski, 2007):

$\tilde{\mathbf{A}}=\left(\mathbf{W}^{\mathbf{t}} \mathbf{W}\right)^{-1} \mathbf{W}^{\mathbf{t}} \mathbf{A W}$

where $\mathbf{A}$ is the averaging kernel matrix on the original (finer) grid and $\mathbf{W}$ is the operator for linear interpolation from the coarse grid to the finer grid. The left side term $\tilde{\mathbf{A}}$ in Eq. (1) is an optimal approximated averaging kernel matrix. Figure 1 illustrates that the retrievals of the three groups are highly sensitive in the lower stratosphere and upper troposphere, and that they have a weaker sensitivity in the lowest part of the troposphere, especially close to the surface. In the case of the LISA retrievals, the constraint has been optimised to give the maximum of freedom in the lower troposphere (keeping reasonable errors) and is therefore weaker compared to the constraint used in the LATMOS retrievals: The DOF for the tropospheric column from the surface up to $11 \mathrm{~km}$ (Table 1) are significantly higher for LISA (0.9-1.2) than for LATMOS (0.3-0.8). Figure 1 also illustrates the dependence of the retrieval sensitivity on surface temperature and the thermal contrast: the higher they are, the larger is the sensitivity, especially in the lower troposphere. The retrieval at LPMAA has also a weak constraint, compared to the retrieval at LATMOS. This results in DOFs as high as those of the retrieval at LISA, but with a smaller sensitivity in the lower troposphere compared to LISA retrievals. The presented LPMAA retrieval is only for high surface temperatures in summer. The DOF for the tropospheric column from the surface up to $11 \mathrm{~km}$ are 1.2 for LPMAA and also 1.2 for the hot case of LISA. Table 1 lists the DOF also for the total and the other partial columns.

The errors on the profile and on the different partial columns have been estimated for the different northern midlatitude bands. They include the contribution of the uncertainty in the spectroscopic parameters, of the uncertainty in the temperature profile, the contribution due to the measurement noise, and the contribution due to the smoothing. In the troposphere, the 1- $\sigma$ total error ranges between 20 and $40 \%$. The error on each retrieved concentration translates to a total error onto the partial columns that ranges between 15 and $30 \%$ for the surface- $6 \mathrm{~km}$ column, between 10 and $15 \%$ for the surface- $11 \mathrm{~km}$ column, and between 5 and $15 \%$ for the surface- $14 \mathrm{~km}$ column. The total error is similar for the different groups.

There are some differences in the conditions and the auxiliary data used by the different groups that could imply difference in the retrieval results (Table 1). First, the spectral window used for the retrieval is either one window (LATMOS, LPMAA) or divided in several windows (LISA). In the latter case, the spectral regions with the strongest water vapour lines are discarded to avoid misfit whereas in the former case, the water vapour lines are fitted simultaneous with ozone. The simultaneous fit should avoid any misrepresentation of the water vapour lines and then should not add any additional perturbation in the retrieval of ozone. The two approaches are then similar for the ozone retrievals. For the retrieval, the information concerning the surface temperature and the temperature profile is necessary. Depending on the group, the surface temperature is either retrieved in a preliminary step (LISA) or during the ozone retrieval (LATMOS, LPMAA). The two approaches are similar as the main aim 
of this fit is to determine the baseline of the spectra (that is finely adjusted during the ozone retrieval at LISA). The temperature profiles used are either extracted from ECMWF and interpolated at the location of the observation (LATMOS, LPMAA) or retrieved in a first step, based on the same interpolated ECMWF a priori (LISA). Comparisons between the different temperature profiles show an agreement within $1-2 \mathrm{~K}$ in the troposphere. Note that this error is mainly randomly distributed. The calculation of the error budget with a constant bias of $1 \mathrm{~K}$ (that gives an upper limit of the temperature uncertainty impact) shows that the error related to the temperature profile uncertainty contributes for about $5 \%$ of the total error. The difference in the temperature profiles used for the ozone retrieval by the different groups should then have only a slight effect and the random character of the error should not affect significantly the comparisons.

\section{Ozone sonde profiles}

Ozone sondes are in situ instruments which are taken from ground up to the stratosphere (until $30 \mathrm{~km}$ or even higher) by a rubber balloon filled with hydrogen. Besides of the electrochemical ozone sensor, most sondes are equipped with GPS (for altitude information) and with temperature and humidity sensors. The high vertical resolution of the measured profiles of about $5 \mathrm{~m}$ is reduced in the stored files to $250 \mathrm{~m}$ for most sondes. The accuracy of the measured ozone concentrations is quoted as about $\pm(5-10) \%$ (Deshler et al., 2008; Smit et al., 2007; Thompson et al., 2003). A major error source is related to the pump-flow dependence on outside pressure. To quantify this error contribution, the ozone total column calculated from the measured ozone profiles is compared with a nearby UV-spectrometer measurement, either ground-based or satellite-based. All Japanese, German, and Belgian ozone sonde profiles are multiplied with a correction factor $(\mathrm{CF})$, defined as the ratio of the two columns.

As the error in the pump-flow increases for low pressures, this method corrects the stratospheric values but may degrade the tropospheric values (Smit et al., 2007). In the present paper, both types of sonde data were used: "corrected" and "uncorrected" ones. No selection of the 'uncorrected' sonde profiles due to the correction factor was made, because the discrepancies between the two columns should mainly occur in the stratosphere. Only sonde profiles that were corrected by more than $15 \%$ were rejected since this large correction may also have affected the tropospheric values.

Because the sondes never reach the top of the atmosphere, an assumption for the remaining part of the profile has to be made to calculate the ozone total column. In the literature (as in the used ozone sonde data), two different approaches are reported: the extrapolation of the profile based on constant mixing ratio (CMR), or the use of the SBUV satellite climatology of McPeters et al. (2007). The advantage of the first method is the individual treatment of each sonde, whereas the second method may be more accurate on average (Thompson et al., 2003). If the sonde data already includes a total column estimate this value was used here, but in case the ozone total column was not given, the CMR method was used. For sonde data where the correction factor was not given, it was calculated from the comparison with daily measured (Level-3) columns of the Ozone Monitoring Instrument (OMI) aboard the NASA EOS-Aura satellite, which are available at ftp://toms.gsfc.nasa.gov/pub/omi/data/ozone. In Table 2 we give the averaged correction factor for each sonde station.

For the sondes used here, three different types of ozone sensors are employed. Most sondes use electrochemical concentration cells (ECC), which measure the oxidation of a potassium iodide (KI) solution by the ozone in the ambient air. The Japanese sondes utilise modified electrochemical concentration cells with carbon anodes (carbon-iodine, $\mathrm{KC}$ ). The profiles of these $\mathrm{KC}$ sondes are always corrected by a nearby UV-measured total column. The ozone sondes launched at Hohenpeißenberg are equipped with BrewerMast (BM) sensors, which are also based on the oxidation of potassium iodide. As for the Japanese sondes, the profiles at Hohenpeißenberg and the profiles at Uccle and Lindenberg (both ECC sensors) are always corrected with a nearby total column measurement. The profiles of the other sondes are left unchanged. A more detailed description of the ozone sonde principles can be found at http://www.fz-juelich.de/ icg/icg-2/josie/ozone_sondes/.

The sondes used in this paper are taken from three archives, namely (1) the World Ozone and Ultraviolet Data Center (WOUDC) (http://www.woudc.org), (2) the Global Monitoring Division (GMD) of NOAA's Earth System Research Laboratory (http://www.esrl.noaa.gov/gmd), and (3) NILU's Atmospheric Database for Interactive Retrieval (NADIR) at Norsk Institutt for Luftforskning (NILU) (http://www.nilu.no/nadir/).

\section{Selection criteria}

The dense spatial coverage of IASI gives us the possibility to use a rather tight coincidence criterium: the footprints of the compared profiles must be inside a square of $\pm 110 \mathrm{~km}$ side length ( \pm 1 degree latitude) around the sonde station. On the contrary, the low frequency of overpasses (two per day) leads to a relatively loose temporal overlap criterium: the time of the IASI measurement must be within 12 hours from the sonde measurement. Note that both these criteria are in agreement with the wide range of coincidence criteria found in the literature (Cortesi et al., 2007; Dupuy et al., 2009; Nassar et al., 2008). The number of spectra that fulfill the coincidence criteria for one overpass can reach 26 (for a nadir angle of zero degree).

Besides the coincidence with the ozone sonde, IASI spectra that were used in the comparisons presented below had 
Table 2. Summary of all sounding stations used in this study.

\begin{tabular}{|c|c|c|c|c|c|c|c|c|}
\hline Name & archive & latitude & longitude & altitude & sensor $^{\mathrm{a}}$ & $\begin{array}{l}\text { correction } \\
\text { factor }^{c}\end{array}$ & applied $^{\mathrm{b}}$ & $\begin{array}{l}\text { used coin- } \\
\text { cidences }^{d}\end{array}$ \\
\hline \multicolumn{9}{|l|}{ mid-latitude sondes } \\
\hline Boulder (Colorado, USA) & GMD & $40.0 \mathrm{~N}$ & $105.2 \mathrm{~W}$ & $1743 \mathrm{~m}$ & $\mathrm{ECC}$ & 0.98 & no & 35 \\
\hline Payerne (Switzerland) & NADIR & $46.8 \mathrm{~N}$ & $7.0 \mathrm{E}$ & $491 \mathrm{~m}$ & ECC & 1.01 & no & 99 \\
\hline STN012 (Sapporo, Japan) & WOUDC & $43.1 \mathrm{~N}$ & $141.3 \mathrm{E}$ & $26 \mathrm{~m}$ & KC-96 & 0.99 & yes & 32 \\
\hline STN014 (Tateno, Japan) & WOUDC & $36.1 \mathrm{~N}$ & $140.1 \mathrm{E}$ & $31 \mathrm{~m}$ & KC-96 & 0.96 & yes & 46 \\
\hline STN107 (Wallops Island, USA) & WOUDC & $37.9 \mathrm{~N}$ & $75.5 \mathrm{~W}$ & $13 \mathrm{~m}$ & ECC & 1.00 & no & 28 \\
\hline STN174e (Lindenberg, Germany) & WOUDC & $52.2 \mathrm{~N}$ & $14.1 \mathrm{E}$ & $112 \mathrm{~m}$ & $\mathrm{ECC}$ & 0.98 & yes & 57 \\
\hline STN221 (Legionowo, Poland) & WOUDC ${ }^{f}$ & $52.4 \mathrm{~N}$ & $21.0 \mathrm{E}$ & $96 \mathrm{~m}$ & $\mathrm{ECC}$ & 0.98 & no & 48 \\
\hline STN308 (Barajas, Spain) & WOUDC & $40.5 \mathrm{~N}$ & $3.6 \mathrm{~W}$ & $631 \mathrm{~m}$ & $\mathrm{ECC}$ & 0.98 & no & 46 \\
\hline STN318 (Valentia Obs., Ireland) & WOUDC & $51.9 \mathrm{~N}$ & $10.2 \mathrm{~W}$ & $14 \mathrm{~m}$ & $\mathrm{ECC}$ & 0.93 & no & 58 \\
\hline \multicolumn{9}{|l|}{$\begin{array}{l}\text { midlatitude sondes } \\
\text { (not processed by LATMOS) }\end{array}$} \\
\hline De Bilt (The Netherlands) & NADIR & $52.1 \mathrm{~N}$ & $5.2 \mathrm{E}$ & $4 \mathrm{~m}$ & ECC & 1.02 & no & 43 \\
\hline Hohenpeißenberg (Germany) & NADIR & $47.8 \mathrm{~N}$ & $11.0 \mathrm{E}$ & $976 \mathrm{~m}$ & $\mathrm{BM}$ & 1.07 & yes & 72 \\
\hline Lerwick (Shetland, Great Britain) & NADIR & $60.1 \mathrm{~N}$ & $1.2 \mathrm{~W}$ & $82 \mathrm{~m}$ & ECC & 1.00 & no & 71 \\
\hline Sodankylä (Finland) & NADIR & $67.4 \mathrm{~N}$ & $26.6 \mathrm{E}$ & $179 \mathrm{~m}$ & ECC & 1.00 & no & 79 \\
\hline Uccle (Belgium) & NADIR & $50.8 \mathrm{~N}$ & $4.4 \mathrm{E}$ & $100 \mathrm{~m}$ & $\mathrm{ECC}$ & 0.97 & yes & 107 \\
\hline
\end{tabular}

to fulfill other criteria as well: first of all, only spectra that passed the cloud-filter (different for all teams) were used. Also, only spectra with nadir angles lower than 32 degree were used to produce equal databases for all retrieval approaches involved. Finally, the number of selected spectra were limited to 9 per coincidence, since this gives a sufficient statistic and reduces computation time. If more than 9 spectra passed all filters, those with the highest surface temperatures were selected. These spectra show typically the best thermal contrast. To have sufficient statistics, only coincidences with four or more spectra passing all filters were used.

The selection of ozone sondes here is limited on those stations where profiles were available for the entire validation period. However, the number of stations in the tropics is very limited and for the existing profiles, the coincident IASI spectra are strongly affected by clouds. We therefore decided to concentrate the present study on northern midlatitudes $\left(30^{\circ} \mathrm{N}-70^{\circ} \mathrm{N}\right.$ latitude). Table 2 gives a summary of all sounding stations, their location, some details on the measurements, and the number of coincidences.

\section{Comparison methodology}

In this section we describe the comparison between the ozone profiles from IASI (retrieved by the different teams presented in section 3) with the profiles measured by balloon sondes (that are assumed to be a good estimate of the real state of the atmosphere). We also introduce the derivation of column amounts from the in situ measured and remotely sensed (IASI) profiles.

Following the formalism of Rodgers (2000), the retrieved profile is $\hat{z}$ :

$\hat{z}=\boldsymbol{x}_{a}+\mathbf{A}\left(\boldsymbol{x}-\boldsymbol{x}_{a}\right)+\boldsymbol{\epsilon}_{z}$

with $\boldsymbol{x}$ the true state of the atmosphere, $\mathbf{A}$ the averaging kernel matrix, and $\boldsymbol{x}_{a}$ the a priori profile. The term $\boldsymbol{\epsilon}_{z}$ sums all errors due to the forward model, the linearisation of the problem and the measurement.

The profile $\boldsymbol{x}_{s}$ measured by the balloon sondes and resampled on the retrieval grid, following Eq. (6), consists of the true atmospheric profile $\boldsymbol{x}$ associated with a measurement error $\epsilon_{s}$.

$\boldsymbol{x}_{s}=\boldsymbol{x}+\boldsymbol{\epsilon}_{s}$

We compare now the balloon sonde profile $\boldsymbol{x}_{s}$ with the retrieved IASI profile $\hat{z}$. The difference $\left(\hat{z}-\boldsymbol{x}_{s}\right)$ contains 
not only error terms, but is strongly dependent on the atmospheric profile, the a priori assumptions and the averaging kernels. Moreover, the compared profiles do not have similar vertical resolution and do not have similar sensitivity to the different parts of the atmosphere. To get rid of these dependencies and of these vertical resolution differences, we transform the sonde measurement in a pseudo retrieved profile $\hat{\boldsymbol{x}}$ (Eq. 2).

$\hat{\boldsymbol{x}}=\boldsymbol{x}_{a}+\mathbf{A}\left(\boldsymbol{x}_{s}-\boldsymbol{x}_{a}\right)$

This operation can be assimilated to a convolution by the averaging kernels. The profile $\hat{\boldsymbol{x}}$ can then be seen as the true profile that should be retrieved by the retrieval method associated with the averaging kernels A.The difference with the actual retrieved profile characterises the performance of the retrieval. However, this profile $\hat{\boldsymbol{x}}$, contrary to $\boldsymbol{x}_{s}$, contains a part of the a priori information. In the extreme case where the observation is not sensitive to the part of the atmosphere considered and then does not bring any information (A would be zero), the transformation of Eq. (4) leads to replace the sonde profile (representing the true state of the atmosphere) by the a priori profile. Similarly the retrieved profile corresponds to the a priori profile in this specific case and the comparison between the two profiles would show a perfect agreement. The extreme situations with A equal to zero or equal to the identity matrix does not occur in the IASI retrievals. The IASI spectra do not provide sufficient information to vertically resolve the ozone profile on a fine altitude grid, and then we are in an intermediate situation with the profile $\hat{\boldsymbol{x}}$ being partly contaminated by the a priori information. The different values of $\mathbf{A}$ for the different teams as illustrated in Fig. 1 show different degrees of contamination. One must be careful with the interpretation of the comparison between the retrieved and the sonde profiles and keep in mind this bad-side effect of the convolution by the averaging kernels that can improve artificially the comparison. That is why we compare the retrieved ozone products to both the convolved sonde products and the raw sonde products in the following.

Finally, the difference between the pseudo retrieved profile $\hat{\boldsymbol{x}}$ and the retrieved profile $\hat{z}$ is an error term, containing only the errors in the retrieval $\epsilon_{z}$ and the errors in the sonde measurement $\boldsymbol{\epsilon}_{s}$.

$$
\begin{aligned}
\hat{z}-\hat{\boldsymbol{x}}= & \left(\boldsymbol{x}_{a}+\mathbf{A}\left(\boldsymbol{x}-\boldsymbol{x}_{a}\right)+\boldsymbol{\epsilon}_{z}\right) \\
& -\left(\boldsymbol{x}_{a}+\mathbf{A}\left(\boldsymbol{x}+\boldsymbol{\epsilon}_{s}-\boldsymbol{x}_{a}\right)\right) \\
= & \boldsymbol{\epsilon}_{z}-\mathbf{A} \boldsymbol{\epsilon}_{s}
\end{aligned}
$$

Making the average over a large number of comparisons separates this error term in its systematic and its random part. The average is an estimate for the systematic error, whereas the standard deviation is an estimate for the random error.

The comparison of volume mixing ratio profiles (see Figs. $4 \mathrm{a}, 4 \mathrm{~b}, 5 \mathrm{a}, 5 \mathrm{~b})$ is performed on the individual retrieval grid of the teams.

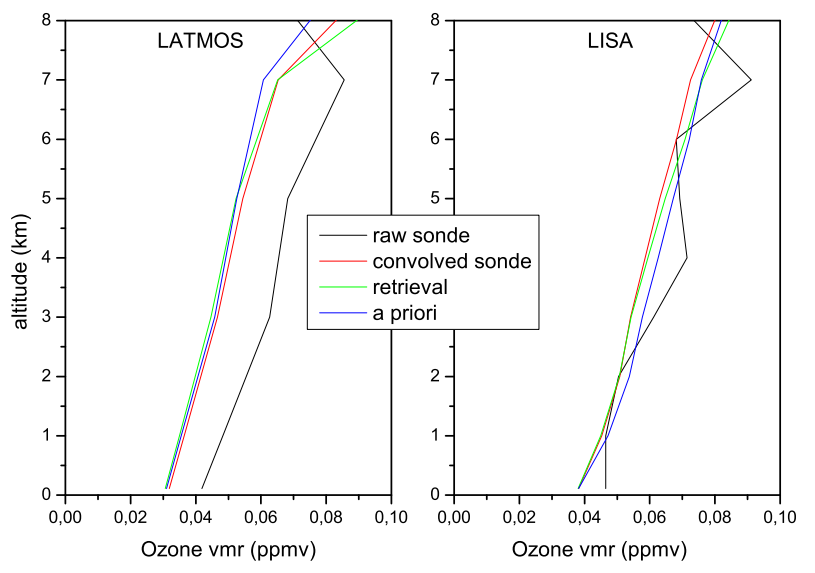

Fig. 2. Bad-side effect of the convolution of the sonde profiles, shown for a selected case for LISA and LATMOS. For low values in the averaging kernel, the convolved profile is pulled towards the a priori profile.

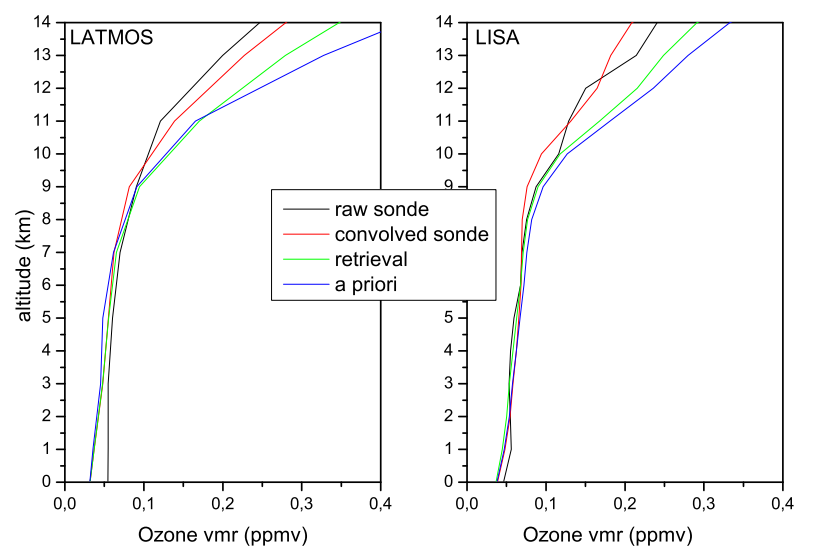

Fig. 3. Reduced retrieval quality in the upper troposphere/lower stratosphere, shown for a selected case for LISA and LATMOS. If the a priori is too far from the true state of the atmosphere (estimated by the sonde profile), the retrieved profiles are also far from the true state.

For the comparison of the "tropospheric" columns, we integrated the pseudo retrieved profile $\hat{\boldsymbol{x}}$ from the surface up to $222.94 \mathrm{hPa}$ to create the sonde column. The profiles retrieved by each team were also integrated from the surface up to $222.94 \mathrm{hPa}$ to give the IASI column. The same steps were performed for the columns from the surface up to $478.54 \mathrm{hPa}$ and $132.49 \mathrm{hPa}$. These three columns are chosen because they correspond to the columns operationally distributed by EUMETSAT.

Note that for the comparison with the results of the neural network at EUMETSAT, no a priori profiles or averaging kernels are available. But as the network was trained to reproduce the real column amounts from the surface up 

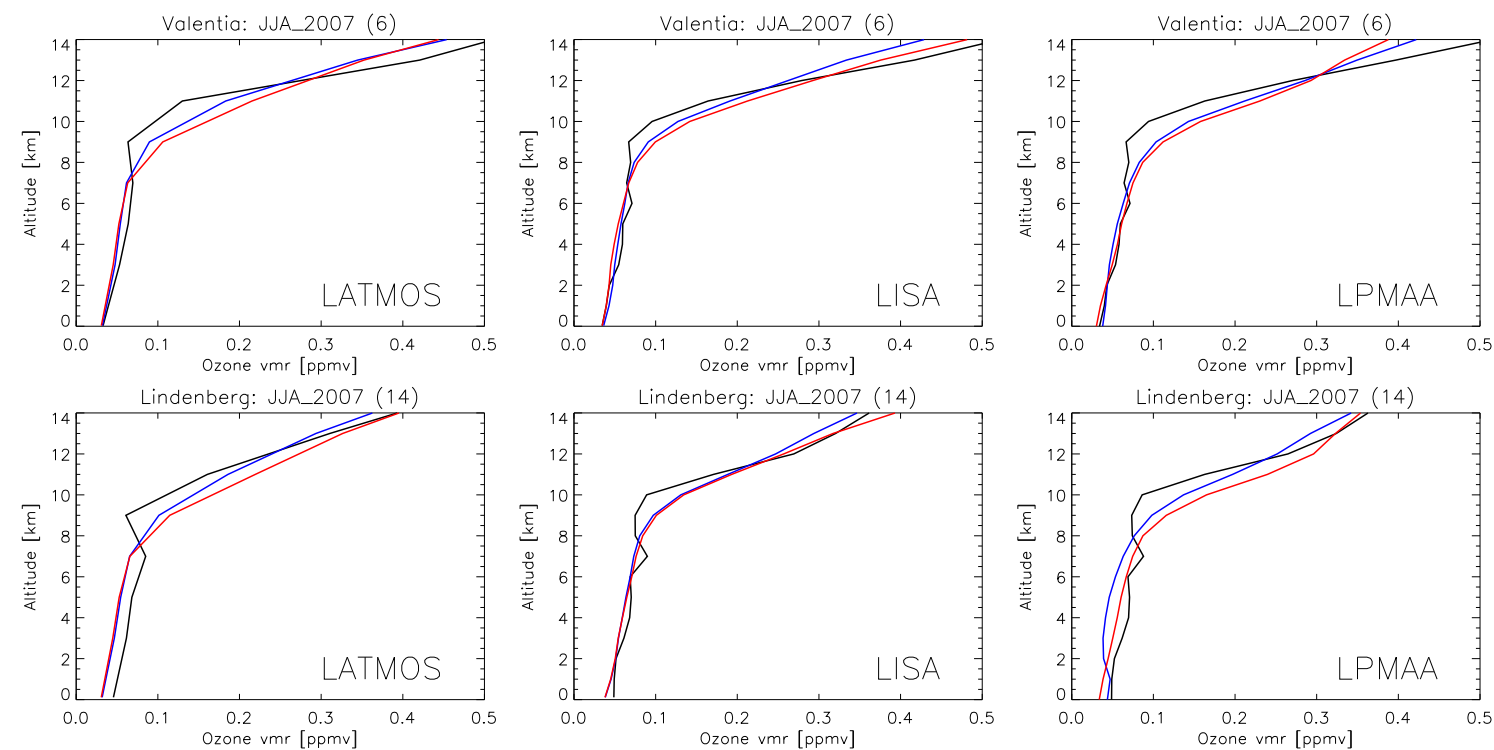

Fig. 4a. Comparison between averages of retrieved IASI-profiles (red), interpolated sonde (black), and AK-smoothed sonde (blue) for two European stations: Valentia (Ireland) and Lindenberg (Germany). The averaging period is summer (JJA) 2007. The left column shows retrievals performed at LATMOS, the middle column shows retrievals performed at LISA, and the right column shows retrievals performed at LPMAA. In parentheses we give the number of used coincidences in the average.
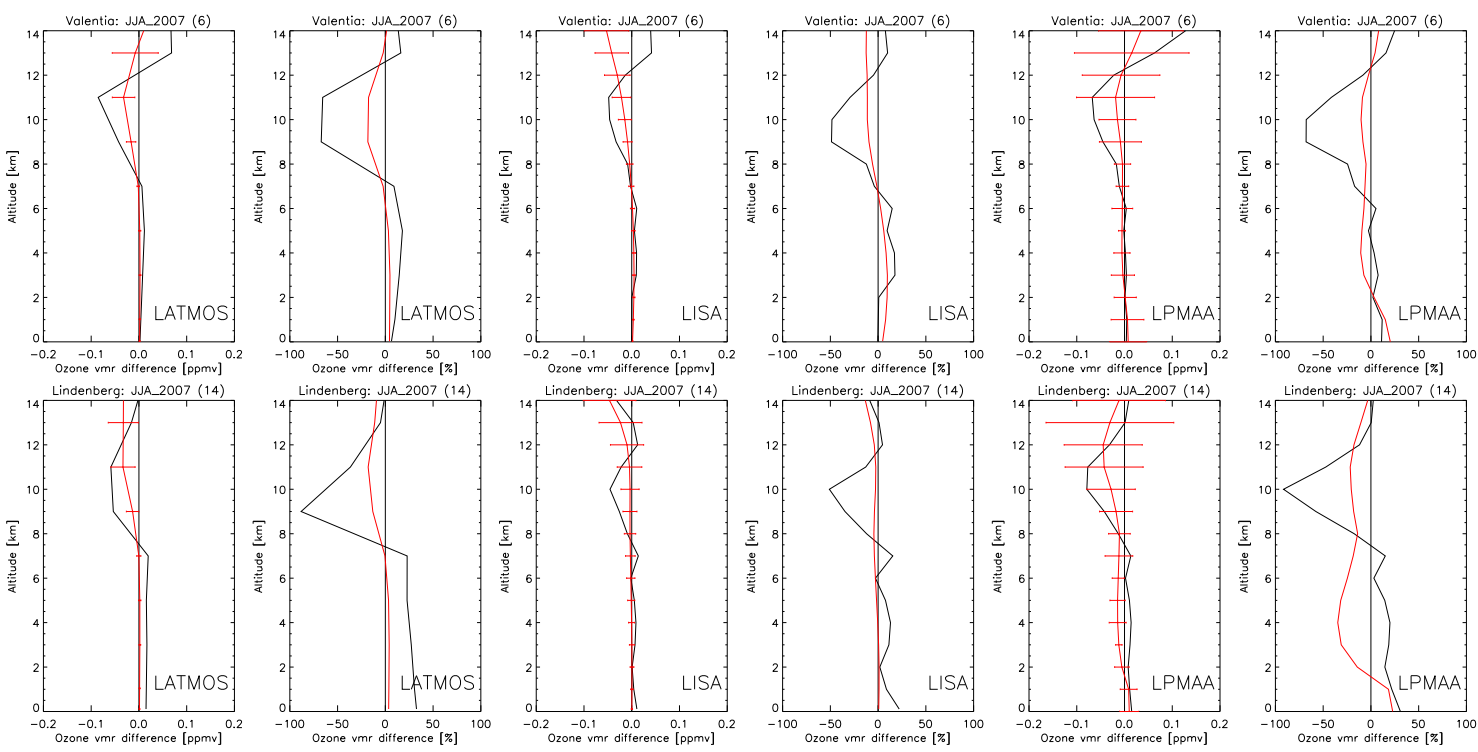

Fig. 4b. Same as Fig. 4a, but with the differences (sonde-retrieval, black) and (AK-smoothed sonde-retrieval, red). The two left columns show retrievals performed at LATMOS, the two middle columns show retrievals performed at LISA, and the two rights show retrievals performed at LPMAA. On the left side (columns 1,3,5) we give the absolute differences, whereas on the right side (columns $2,4,6)$ the relative differences are shown. The relative differences are given in percent and calculated with respect to the sonde profiles, i.e. (sonde - retrieval)/sonde and (AK-smoothed sonde - retrieval)/AK-smoothed sonde. The colours of the relative differences are according to the absolute differences. The bars give the variability $(1 \sigma)$ of the difference, not the errors associated with the profiles. 

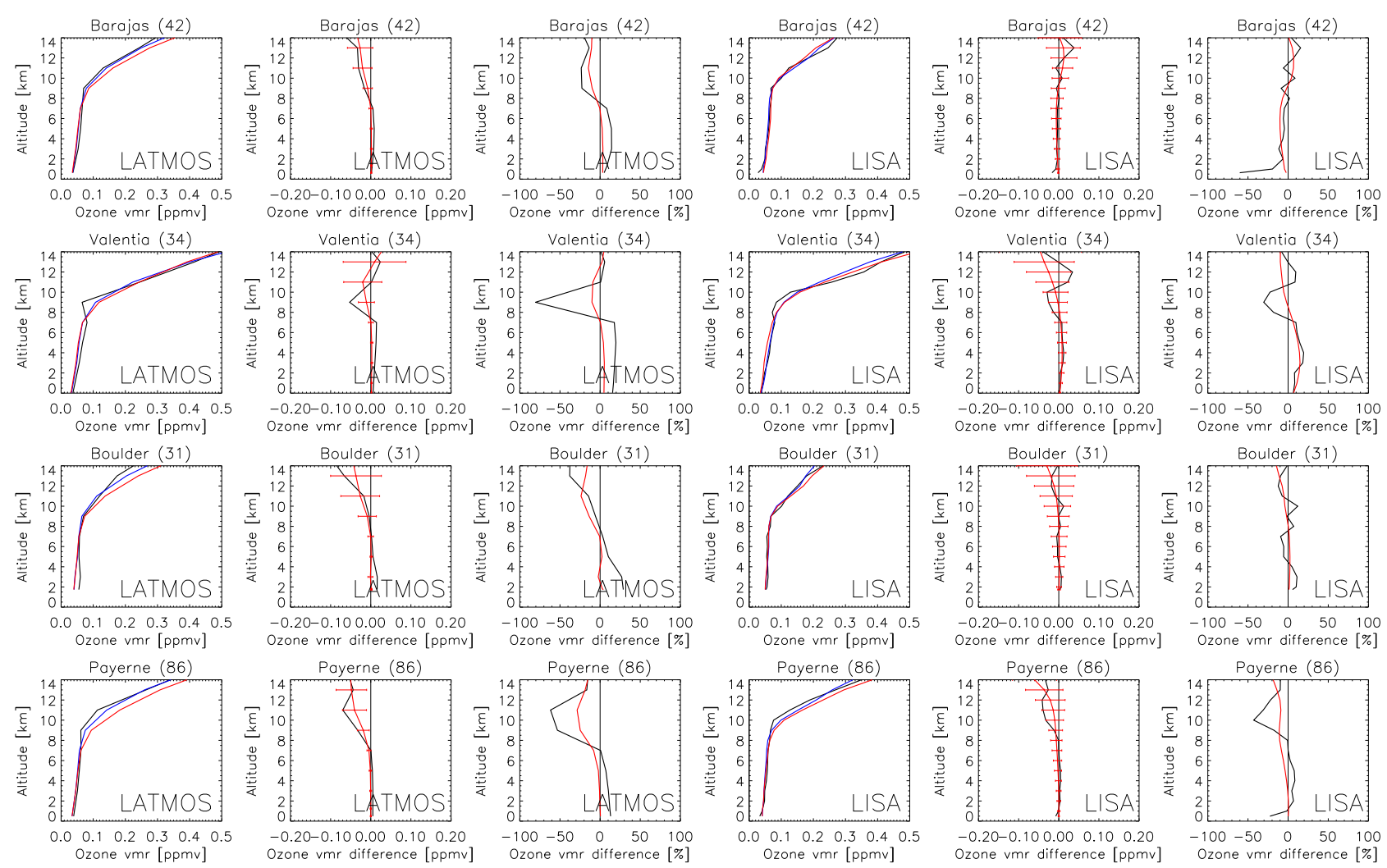

Fig. 5a. This figure shows the averaged profiles and differences for all mid-latitude stations processed by LATMOS and LISA. The averaging period is 06.2007-08.2008. The three left columns show the retrievals performed at LATMOS, the three right columns show LISA. Each packet of three columns is organised with the profiles in the left column, the absolut differences in the middle column, and the relative differences in the right column. The relative differences are given in percent and calculated with respect to the sonde profiles, i.e. (sonderetrieval)/sonde and (AK-smoothed sonde-retrieval)/AK-smoothed sonde. The colours of the profiles are: retrieved IASI-profiles in red, interpolated sonde in black, and AK-smoothed sonde in blue. The colours of the absolut differences are: sonde-retrieval in black and AKsmoothed sonde-retrieval in red. The relative differences are coloured accordingly. In parentheses we give the number of used coincidences in the average, the bars give the variability $(1 \sigma)$ of the difference.

to $222.94 \mathrm{hPa}$, we compared the retrieved columns with the integrated raw sonde profile also from the surface up to $222.94 \mathrm{hPa}$. We similarly calculated the columns from the surface up to $478.54 \mathrm{hPa}$ and $132.49 \mathrm{hPa}$.

\subsection{Grid change from the fine sonde grid to the coarse retrieval grid}

The retrievals are performed on a coarse grid, compared to the sonde measurement. Therefore one cannot use the raw sonde measurement $\boldsymbol{x}_{s \text {,raw }}$ for $\boldsymbol{x}_{s}$ in Eq. (4). Following Rodgers (2000) we best approximate the sonde using Eq. (6).

$\boldsymbol{x}_{s}=\left(\mathbf{W}^{\mathbf{t}} \mathbf{W}\right)^{-1} \mathbf{W}^{\mathbf{t}} \boldsymbol{x}_{s, \text { raw }}$

where $\boldsymbol{x}_{s, \text { raw }}$ is the measured sonde profile and $\mathbf{W}$ is the operator for linear interpolation from the coarse retrieval grid to the finer sonde grid. The left side term $\boldsymbol{x}_{s}$ in Eq. (6) is an optimal approximated sonde profile on the retrieval grid.

\section{Results and discussion}

In this section we describe the comparison between the remotely-sensed ozone profiles and tropospheric columns (IASI) with the in situ measured data (balloon sondes). The comparison is threefold: (1) we compare mean profiles for each sonde stations with the coincident mean IASI retrieved profiles, (2) we compare the individual IASI partial columns with their sonde equivalent, and (3) we investigate the statistical distribution of the difference between IASI and sonde partial columns.

\subsection{Comparison of mean profiles}

Figure $4 \mathrm{a}$ shows the mean profiles retrieved at LATMOS, LISA, and LPMAA together with the mean sonde measurements for two selected European sonde locations. The mean sonde profiles convolved with the averaging kernels - the expected retrieved profiles $\hat{\boldsymbol{x}}$ using Eq. (4) - is also given. For 

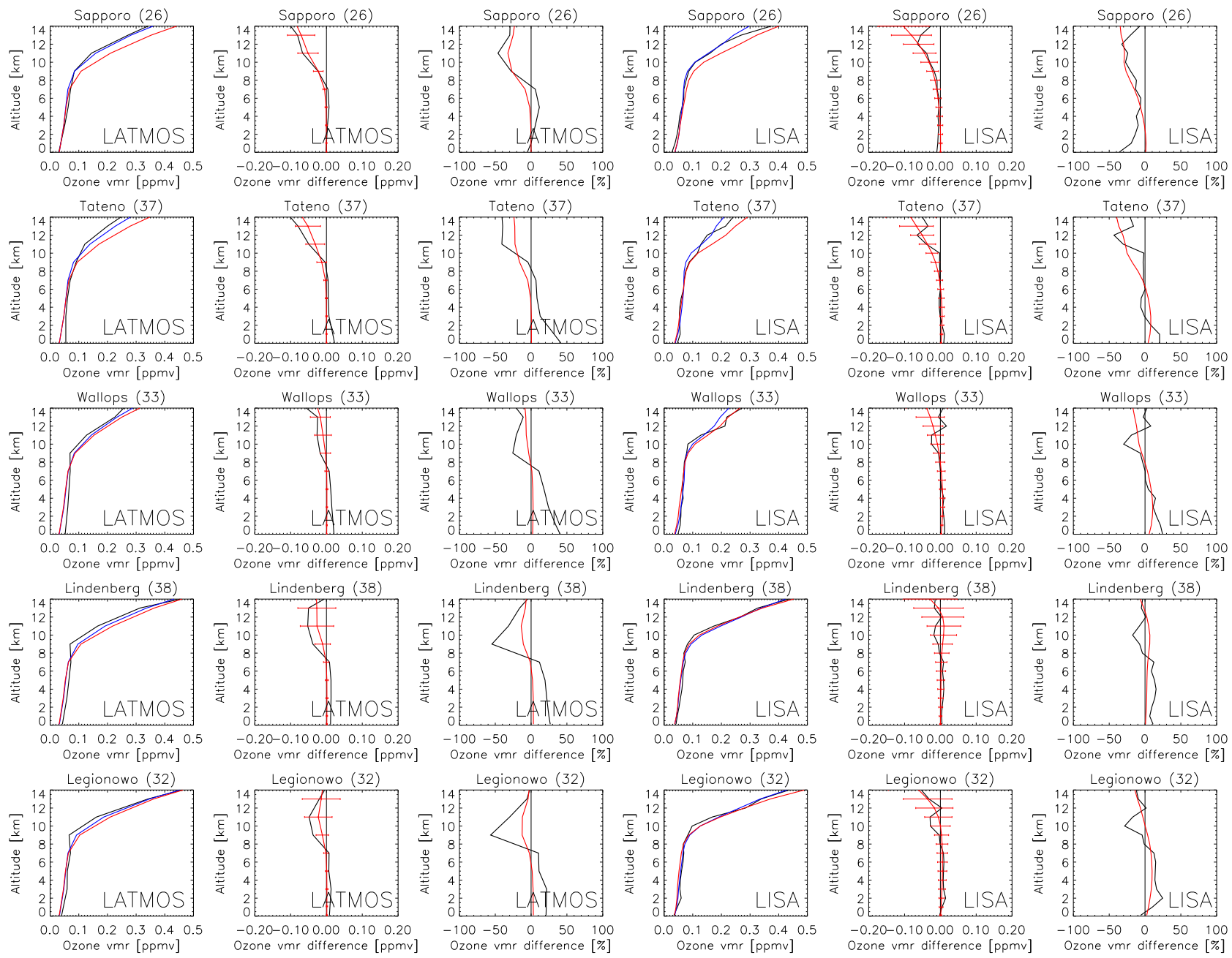

Fig. 5b. Same as Fig. 5a, but with other locations.

the comparison with each retrieved profile, the sonde profile is convolved using the corresponding averaging kernels and a priori profiles of each team. The averages are then performed over the summer period 2007, using coincidences which are cloud-free for the three teams. Figure $4 \mathrm{~b}$ shows the differences between the retrieved profiles and the sonde profiles or the convolved sonde profiles for the three teams. The variability $(1 \sigma)$ of the difference between the retrieved profile and the convolved sonde profile is indicated as bars in Fig. 4b. The comparison between the raw sonde and the convolved sonde profiles in Fig. 4a illustrates the effect of the low vertical resolution of the IASI instrument. In particular, the details and the sharp changes near the tropopause are largely smoothed and cannot be resolved by instruments of IASI type. The comparison with the retrieved IASI profiles shows a general better agreement for an altitude smaller than $8 \mathrm{~km}$, especially for the LATMOS retrieval (Fig. 4b). The difference between the mean convolved sonde profiles and the mean profiles retrieved at LATMOS is about 3\% below $8 \mathrm{~km}$ and about $13 \%$ on average between 8 and $14 \mathrm{~km}$ for the two stations presented in Fig. 4b. The differences are larger for the comparison with the raw sonde profiles (from 12 to $27 \%$ on average below $8 \mathrm{~km}$ and from 38 to $43 \%$ on average above $8 \mathrm{~km}$ ) but they are only indicative because the vertical resolution of the compared profiles is different (the profiles do not represent similarly the same part of atmosphere). For the LISA and LPMAA retrievals, the differences between the lower and the upper part of the troposphere are less pronounced. The difference between the mean convolved sonde profile and the mean profiles retrieved at LISA ranges from 1 to $5 \%$ below $8 \mathrm{~km}$ and from 5 to $11 \%$ above $8 \mathrm{~km}$. The comparison with the raw sonde profiles leads to less differences for the LISA retrievals (from 7 to $18 \%$ ) compared to the LATMOS retrievals and are relatively similar to the results 

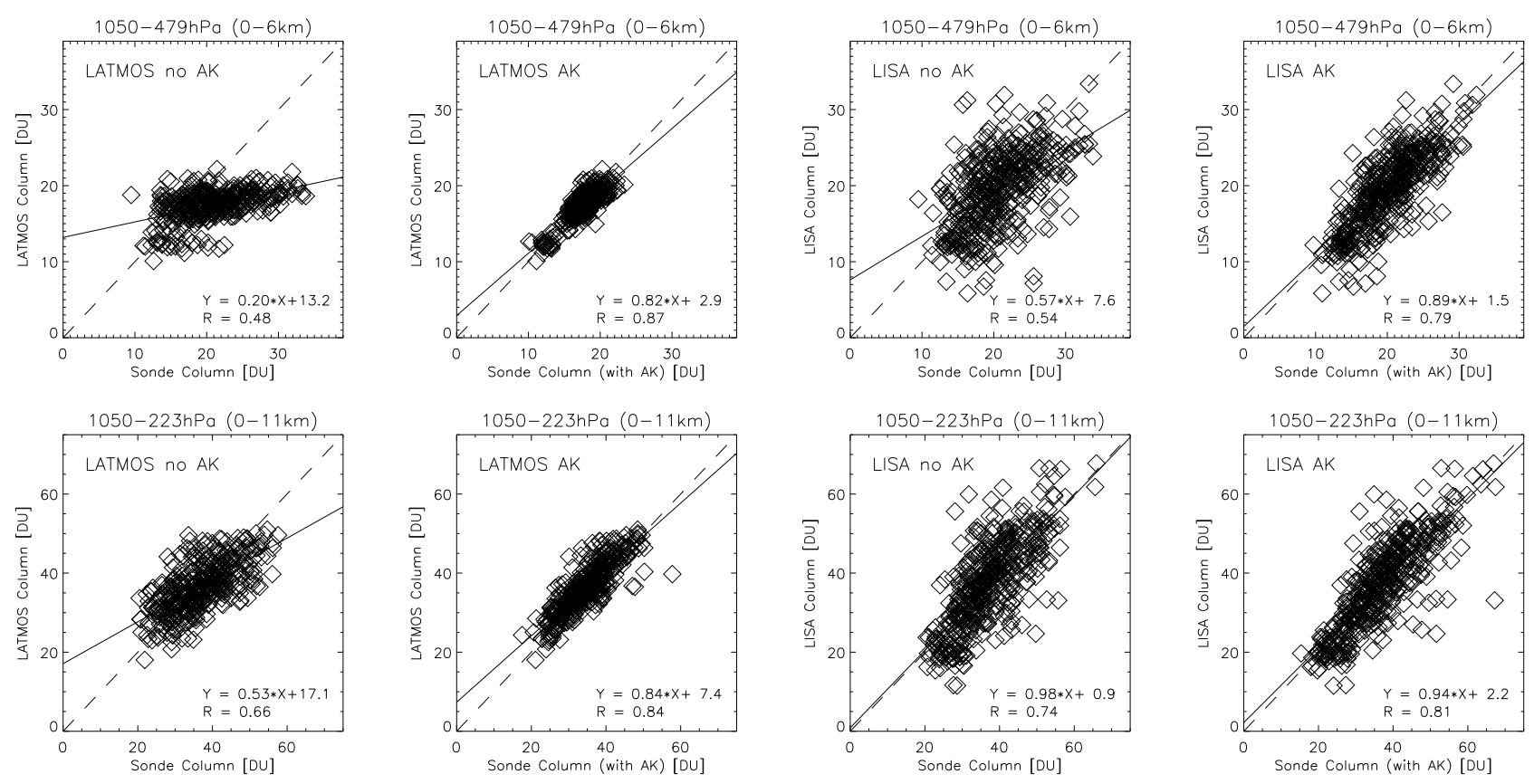

Fig. 6. Comparison of the IASI-retrievals performed at LISA and LATMOS for mid-latitude stations for the period June 2007-August 2008. The plots show the IASI derived columns versus the sonde columns. In the fist line the columns surface- $6 \mathrm{~km}$ are given, in the second line the columns surface-11 km. The four left plots show the results for LATMOS, the right plots are for LISA. The plots indicated with 'no AK' compare the IASI columns with the columns calculated from the raw sonde profile, whereas the plots indicated 'AK' compare IASI with the columns derived from the sonde profiles convolved with the averaging kernels (Eq. 4).

obtained with the convolved sondes. The difference between the mean convolved sonde profile and the mean profiles retrieved at LPMAA ranges from 1 to $14 \%$ below $8 \mathrm{~km}$ and from 3 to $15 \%$ above $8 \mathrm{~km}$. The differences for the comparison of these LPMAA retrievals with the raw sonde profiles are similiar below $8 \mathrm{~km}$ (from 1 to $13 \%$ ) and higher above $8 \mathrm{~km}$ (from 24 to $32 \%$ ), compared to the difference to the convolved sondes.

Figure $5 \mathrm{a}$ and $5 \mathrm{~b}$ show the mean profiles retrieved at LATMOS and LISA together with the mean sonde measurements (raw and convolved) for the northern latitude sonde locations. The averaging periode is June 2007 to August 2008. These figures also show that the LISA retrieval process (application of Eq. 4) weakly affects the sonde profile. The different behaviour between the two retrievals certainly arises from the difference in the used regularisation and a priori assumptions. The LATMOS retrieval is more constrained in the lower troposphere (Fig. 1) and then is likely more affected by the badside effect of the smoothing (Eq. 4) discussed in Sect. 6. Figure 2 illustrates this effect with the retrieved profile and the convolved sonde profile pulled to the a priori profile. This effect is also likely partly responsible for the smaller variability reported for the difference between the convolved sonde profiles and the retrieved profiles. The regularisation applied for the LISA retrievals leads to a smaller constraint in the lower troposphere (Fig. 1) and the convolved sonde profile is less affected (Fig. 2). The constraint has been chosen to optimise the sensitivity in the lower troposphere but the counterpart of this rises in slightly larger errors in the retrieval that take part of the larger variability visible in the difference (Fig. 5a and $5 b$ ). It is interesting to note that the difference between the sonde profiles and the retrieved profiles of both teams is largely correlated with the difference between the sonde profiles and the a priori profiles used. The larger difference observed in the upper troposphere for some stations (Fig. 5a and $5 b$ ) can be related for most of the cases to a difference between the a priori profile and the sonde profile too large in this altitude range. The first guess and the a priori profile (identical in the retrievals) are too far from the solution to allow a good retrieval (Fig. 3). Despite the differences underlined above, the mean profiles retrieved by LATMOS, LISA, and LPMAA are in good agreement with the sonde profiles (5-25\% on average). It is worth to recall that the mean errors on the retrieved mixing ratios are about $30 \%$ and that the retrieval of tropospheric ozone from nadir measurement is a challenge.

\subsection{Comparison of individual partial columns}

To investigate the quality of the individual profiles, we compared the "tropospheric" ozone columns of the different retrievals and the sonde measurements. The tropospheric 

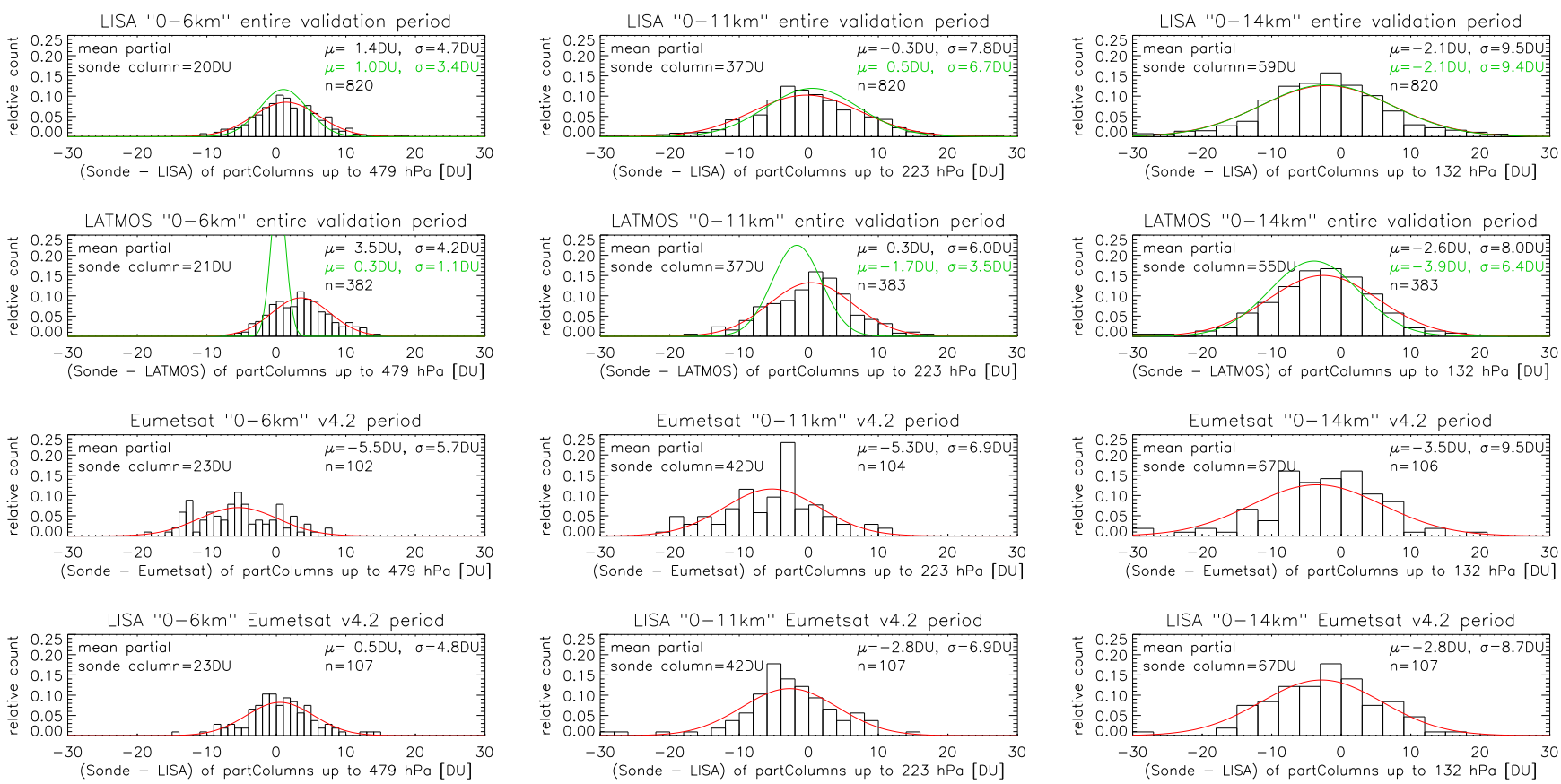

Fig. 7. $\operatorname{Bias}(\mu)$ and variability $(\sigma)$ of the differences between the IASI-retrievals (LATMOS, LISA, and EUMETSAT) and the ozone sondes, calculated from $n$ coincidences for the three partial columns: surface- $6 \mathrm{~km}$, surface- $11 \mathrm{~km}$, and surface- $14 \mathrm{~km}$. We show only the histograms of the absolute differences with the raw sonde measurements. The fitted normal distributions are given for the raw sonde comparison (red) and for the comparison with the AK-convolved sonde profiles (green). We refer to the text and to Table 3.

columns here are defined as the column from the surface up to $223 \mathrm{hPa}$ (about surface- $11 \mathrm{~km}$ ) and $478.54 \mathrm{hPa}$ (about surface-6 km), respectively. We have chosen the tropospheric levels that are available for the EUMETSAT retrieval. The mean columnar ozone amount is about $40 \mathrm{DU}$ and $20 \mathrm{DU}$, respectively, justifying the choice of the columns. The tropopause height is not considered in the selection of the column heights. In most cases, only a small or no contribution of the lowest stratosphere is in the column surface$11 \mathrm{~km}$

The degrees of freedom for the thicker column are about one. In Fig. 6 we compare the columns retrieved at LATMOS and at LISA with sonde columns for the mid-latitude stations processed by LATMOS (see Table 2), and for the time period from June 2007 to August 2008. Once again we compare the IASI retrieved products with both the raw and the convolved sonde data (Fig. 6). The comparison with the raw sonde columns shows a medium agreement, especially for the lower columns. The correlation coefficient is relatively small for the surface- $6 \mathrm{~km}$ columns ( 0.48 for the LATMOS retrievals and 0.54 for the LISA retrievals) as well as the slope of the linear regression ( 0.2 for LATMOS and 0.57 for LISA). The agreement improves when comparing the surface $-11 \mathrm{~km}$ columns that have a DOF close to unity and then more information included in. The correlation coefficient is then 0.66 for LATMOS and 0.74 for LISA and the slope values are 0.53 and 0.98 for LATMOS and LISA, respectively. The comparison with the convolved sondes shows a better agreement. The correlation coefficient ranges between 0.8 and 0.9 for the surface- 6 and surface $-11 \mathrm{~km}$ columns of both teams' retrievals (Fig. 6). The slope is 0.82 and 0.84 for the surface- 6 and surface $-11 \mathrm{~km}$ columns, respectively, for LATMOS and 0.89 and 0.94 for LISA. The better agreement when comparing with the convolved sonde columns arises mainly because products with similar vertical resolution are compared. That is not the case when comparing with the raw sonde columns. However, the bad-side effect of the smoothing (the convolution) of the sonde profiles with the IASI averaging kernels, that can bring the sonde to the a priori, likely plays a significant part in this better agreement. As we previously explain this effect is certainly a little more present in the LATMOS retrievals due to a stronger constraint to the a priori profile. The larger correlation coefficients compared to LISA likely reflect this effect partially. As for the profile comparisons (section 7.1), the LISA retrievals compared to the sonde show a larger variability than the LATMOS retrievals. This results from the constraint used in the LISA retrievals that gives more freedom in the troposphere, especially the lower troposphere, but leads to a larger variability. The comparisons performed on the individual columns and on the mean profiles (previous section) suggest that on average (mean profiles) the two products (LATMOS and LISA) 

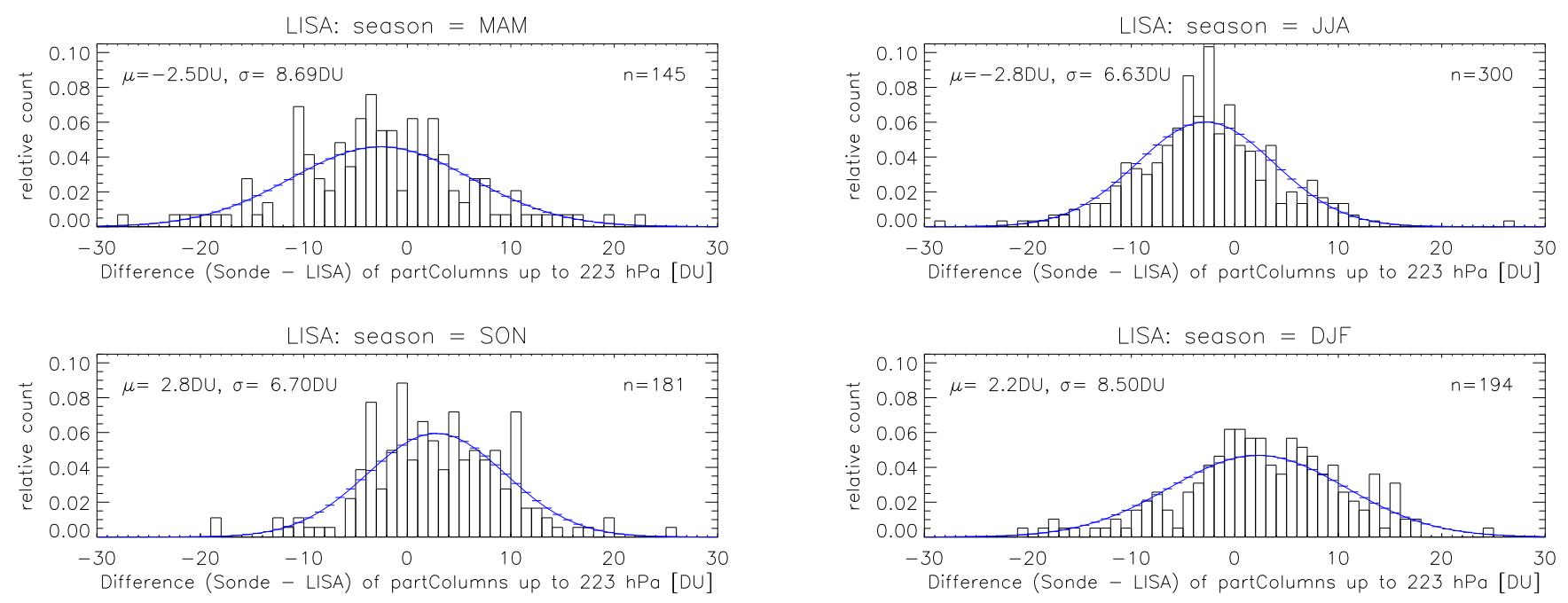

Fig. 8. $\operatorname{Bias}(\mu)$ and variability $(\sigma)$ of the differences between the columns from the surface up to about $11 \mathrm{~km}$ from the LISA-retrievals and the sonde measurements for the four seasons, calculated from $\mathrm{n}$ coincidences.

have similar performances, on individual retrievals the LISA products seem to be less affected by the bad-side effect of the smoothing.

\subsection{Statistical comparison of partial columns}

We also studied the distribution of the partial column differences between the retrievals and the sonde measurements. Figure 7 shows histogram plots for the retrievals of midlatitude coincidences performed at LATMOS and LISA for the period from June 2007 to August 2008, and for the retrievals at EUMETSAT and LISA for the EUMETSAT v4.2 period from February 2008 to August 2008. We included all IASI profiles in the statistic, which have been processed by the individual teams and passed their own cloud-filters. No averaging kernels and a priori profiles are available for the neural network retrieval performed by EUMETSAT. Because we want to show equal treatment of all retrievals, we have not done any convolution of the sonde measurement, also for the comparisons with the retrievals of LATMOS and LISA. The statistical parameters (mean and $1 \sigma$ variability) are derived assuming a Gaussian distribution and summarised in Table 3. For LISA and LATMOS retrievals we derived also the statistics for the differences to the convolved sonde profiles. We overplotted the histograms (green curve in Fig. 7) with these distributions and list their parameters in Table 3.

If one compares the numerical inversions (LATMOS and LISA) with the raw sonde data, the bias (that represents an estimate of the systematic error) is positive and ranges between 5.5 and $13.5 \%$ for the surface- $6 \mathrm{~km}$ columns. It becomes negative and less than $1 \%$ for the surface $-11 \mathrm{~km}$ columns. The bias remains negative for the surface- $14 \mathrm{~km}$ columns and ranges between 4 and $7 \%$. The variability that represents an estimate of the random error (including both the error of the retrieval and the error of the sonde measurement) is larger for the LISA retrieval both for the surface6 and the surface $-11 \mathrm{~km}$ columns. This is again related to the weaker constraint in the lower troposphere in the LISA retrieval that brings more DOF but also slightly more variability and errors. Another difference between the two comparisons (LATMOS and LISA) that can explain also a part of the larger variability in the LISA products is the larger number of stations considered in the comparisons. The variability values (Table 3 ) are however consistent with the errors (retrieval and sonde) for the retrievals of both teams. When comparing with the convolved sonde columns, the bias remains similar for LISA retrievals but is significantly changed for the LATMOS retrievals. The bias is in particular reduced for the lower columns (from $13.5 \%$ to $1.3 \%$ ) and increased for the surface- $11 \mathrm{~km}$ columns (from $0.8 \%$ to $5.6 \%$ in absolute). The variability of the differences is reduced for both teams' retrievals (Table 3). The variability of LISA remains consistent with the mean errors on the columns whereas the variability of LATMOS is much lower, especially for the surface- $6 \mathrm{~km}$ columns (Table 3 ) and reveals the bad-side effect of the sonde convolution that can reduce artificially the variability and improve the agreement between the different datasets compared.

Nevertheless, the retrievals at LATMOS and LISA have small biases for the tropospheric columns (less than $2 \mathrm{DU}$, less than 10\%) compared to the mean errors in the columns, and the variability is consistent with the expected error budget. In contrast, the retrieval at EUMETSAT shows a large negative bias of about 5.5 DU for the two tropospheric columns (Table 3). This is in agreement with the validation study made by Oduleye et al. (2008), but greater than 
Table 3. Summary of the statistics of the distribution of the differences between ozone partial columns retrieved from IASI and from sonde measurements. For the different teams, we present the average $(\mu)$ and the standard deviation $(\sigma)$ for both, the comparison of IASI with the raw sonde profiles and with the sonde profile convolved with the averaging kernels. A graphical presentation of the statistics is shown in Fig. 7

\begin{tabular}{|c|c|c|c|c|c|c|c|c|c|c|c|c|c|}
\hline \multirow{3}{*}{$\begin{array}{l}\text { team } \\
\text { sonde selection }\end{array}$} & & \multicolumn{6}{|c|}{ with raw sonde } & \multicolumn{6}{|c|}{ with convolved sonde } \\
\hline & & \multicolumn{2}{|c|}{ surface- $6 \mathrm{~km}$} & \multicolumn{2}{|c|}{ surface- $-11 \mathrm{~km}$} & \multicolumn{2}{|c|}{ surface-14 km } & \multicolumn{2}{|c|}{ surface- $6 \mathrm{~km}$} & \multicolumn{2}{|c|}{ surface-11 km } & \multicolumn{2}{|c|}{ surface- $14 \mathrm{~km}$} \\
\hline & & $\mu^{\mathrm{a}}$ & $\sigma^{\mathrm{a}}$ & $\mu$ & $\sigma$ & $\mu$ & $\sigma$ & $\mu$ & $\sigma$ & $\mu$ & $\sigma$ & $\mu$ & $\sigma$ \\
\hline LISA $\quad 6.07-8.08$ & {$[\mathrm{DU}]$} & 1.4 & 4.7 & -0.3 & 7.8 & -2.1 & 9.5 & 1.0 & 3.4 & 0.5 & 6.7 & -2.1 & 9.4 \\
\hline all mid-latitude sondes & {$[\%]$} & 5.5 & 24.1 & -0.9 & 22.0 & -4.1 & 16.3 & 4.8 & 18.0 & 1.1 & 17.8 & -4.1 & 15.7 \\
\hline LATMOS $\quad 6.07-8.08$ & {$[\mathrm{DU}]$} & 3.5 & 4.2 & 0.3 & 6.0 & -2.6 & 8.0 & 0.3 & 1.1 & -1.7 & 3.5 & -3.9 & 6.4 \\
\hline selected $^{\mathrm{b}}$ mid-lat. sondes & {$[\%]$} & 13.5 & 17.7 & 0.8 & 17.6 & -6.7 & 15.6 & 1.3 & 6.1 & -5.6 & 10.5 & -8.4 & 11.6 \\
\hline EUMETSAT & {$[\mathrm{DU}]$} & -5.5 & 5.7 & -5.3 & 6.9 & -3.5 & 9.5 & - & - & - & - & - & - \\
\hline all mid-latitude sondes & {$[\%]$} & -26.3 & 27.1 & -14.0 & 18.1 & -7.5 & 17.1 & - & - & - & - & - & - \\
\hline $2.08-8.08$ & {$[\mathrm{DU}]$} & 0.5 & 4.8 & -2.8 & 6.9 & -2.8 & 8.7 & -0.2 & 3.4 & -2.1 & 6.0 & -5.1 & 8.0 \\
\hline all mid-latitude sondes & {$[\%]$} & 2.3 & 22.4 & -7.7 & 18.9 & -4.9 & 14.8 & -2.3 & 16.5 & -6.0 & 15.8 & -8.4 & 13.8 \\
\hline
\end{tabular}

a the distribution of (sonde-IASI) is assumed to be Gaussian with $\mu$ : mean and $\sigma$ : standard deviation;

b e.g. the upper part in Table 2.

the target accuracy. We limited the comparison with LISA retrievals on the same period as the comparison with EUMETSAT (4th line in Table 3), to exclude seasonal effects or other problems that could have taken place during this special time. The retrieval at LISA shows a random error distribution of Gaussian-type (Fig. 7) whereas the distribution obtained with the EUMETSAT retrievals deviates from a normal-distribution especially for the surface- $6 \mathrm{~km}$ columns. Moreover, the mean difference between the LISA retrieval and the sonde for this time period is much lower than for EUMETSAT comparison, especially for the lowest partial column (Table 3). Both bias and variability of LISA are consistent with the results for the entire validation period. The comparison of the columns from the surface up to $14 \mathrm{~km}$ shows a similar quality of the EUMETSAT, LATMOS, and LISA retrievals with a bias of about $3 \mathrm{DU}$ and a variability of about $16 \%$.

To test the dependency on seasonal atmospheric variations, we made individual histograms for the columns from the surface up to $11 \mathrm{~km}$ for the four seasons (Fig. 8). The retrieval at LISA has a small dependency on the seasons, with small but varying biases and standard deviations being a little bit higher in winter and spring than in summer and autumn. Interpreting the bias as expectation value of a normal-distribution, the associated error (e.g. for DJF) is $\sigma_{\mu}=\sigma / \sqrt{n}=8.5 \mathrm{DU} / \sqrt{194}=0.6 \mathrm{DU}$. This may partly explain the variability of the biases.

\subsection{Seasonal variations of the LISA partial columns}

In Fig. 9 we show all the individual columns (LISA retrievals and unconvolved sonde measurements, red and blue symbols, respectively) grouped in months and latitude bands as in the Labow, Logan, McPeters (LLM) climatology (McPeters et al., 2007). We give also the monthly means (coloured lines), the column of the a priori profile (dashed black line), and the climatological means with their variability $(3 \sigma$, black line with bars). Note in particular that the retrievals at LISA are not sticking at the constant a priori and reproduce well the annual variation of ozone in the mid-latitudes. The dispersion of the retrieved value for each month is consistent with the variability prescribed by the climatology.

\section{Conclusions}

In this study we have compared the IASI ozone retrieval of three research teams and from the (pre-)operational and official processing at EUMETSAT to a large set of ozone sondes profiles at northern mid-latitudes. The goal was to quantify the systematic and the random errors of the different algorithms. The difference of the retrieved profiles to the sondes profiles contains three kinds of errors: the measurement error of the ozone sonde (5-10\%), the retrieval error (20$40 \%$ ) and the error of the a priori profile. The application of the retrieval operator to the sonde profile prior to the difference eliminates the a priori error. In the case of the retrieval at LISA the a priori error is quite small (less than $1 \mathrm{DU}$ in average, for all partial columns). Compared to the retrieval at LISA, the stronger regularisation of the retrieval at LATMOS leads to a smaller variability in the comparison with the convolved sonde profiles (e.g. 6.1\% for LATMOS instead of $17.7 \%$ for LISA, for the columns surface- $6 \mathrm{~km}$ ), but to a higher bias in the comparison with the raw sondes (e.g. 3.5 DU for LATMOS instead of 0.3 DU for LISA, also for the columns surface- $6 \mathrm{~km}$ ). The systematic bias of the 

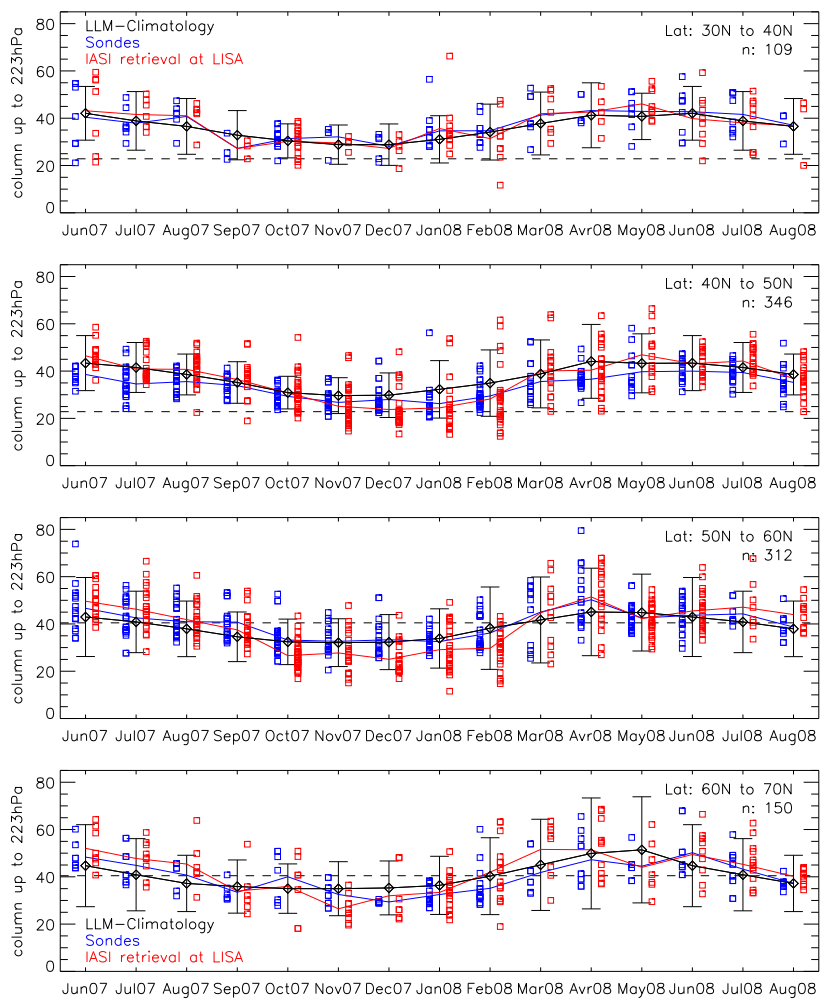

Fig. 9. Annual variability of the ozone column from the surface up to $223 \mathrm{hPa}$ for different northern latitude bands. We show the individual measurements (symbols) together with the means (lines). We give the sonde measurements (blue), the IASI-retrieval performed at LISA (red), and the Labow, Logan, McPeters (LLM) climatology (McPeters et al., 2007, black). The bars indicate the variability ( $3 \sigma$ ) given in the climatology. The dashed line indicates the column of the a priori profile. The number of used coincidences is $n$.

retrieval at LISA shows a small dependency on the season, whereas the bias is generally small (less than $3 \mathrm{DU}$ for the columns from the surface up to $223 \mathrm{hPa}$ ). The variability ( $17.8 \%$ for the columns from the surface up to $223 \mathrm{hPa}$ ) is consistent with the upper bound of the estimated combined error (11-18\%) of the retrieval (10-15\%) and the sonde (5$10 \%)$. For the compared cases, the profile retrievals at LATMOS, LISA, and LPMAA show no significant differences. This indicates that the achievable retrieval quality, which is limited by atmospheric and instrumental properties, is obtained for these retrievals. The comparisons performed on the individual columns (Sect. 7.2 and 7.3) and on the mean profiles (section 7.1) suggest that on average (mean profiles) the three products (LATMOS, LISA, and LPMAA) have similar performances but on individual retrievals the LISA and LPMAA products seem to be less affected by the bad-side effect of the smoothing. The retrieval at EUMETSAT is still in a pre-operational developing phase. In the comparison we used the v4.2 version, which was applied to the data until
11 August 2008. The EUMETSAT tropospheric columns are higher than the sonde columns by more than $5 \mathrm{DU}$ on average with a variability of about $20 \%$. This is slightly worse than the target accuracy. The EUMETSAT columns from the surface up to $14 \mathrm{~km}$ show a similar quality to LATMOS and LISA retrievals with a bias of about 3 DU and a variability of about $17 \%$. EUMETSAT changed the training of the neural network (August et al., 2008) to enhance the retrieval quality. The validation of the subsequent version $\mathrm{v} 4.3$ (in use until January 2009) is an ongoing process and can not be presented in this study due to the insufficient number of available sonde data for this period.

Acknowledgements. IASI has been developed and built under the responsibility of the Centre National d'Etudes Spatiales (CNES, France). It is flown aboard the Metop satellites as part of the EUMETSAT Polar System. The IASI L1C and L2 data have been received through the EUMETCast near real time data distribution service and provided by the Ether French atmospheric database (http://ether.ipsl.jussieu.fr). The presented study has been supported by CNES in the frame of the IASI-TOSCA project. The authors are grateful to INSU for publication support. The temperature and altitude fields have been taken from ECMWF, and the ozone total columns of OMI from NASA (ftp://toms.gsfc.nasa.gov/pub/omi/data/ozone/). The ozone sonde data have been taken from the following archives: the World Ozone and Ultraviolet Data Center (WOUDC) (http://www.woudc.org), the Global Monitoring Division (GMD) of the Earth System Research Laboratory (http://www.esrl.noaa.gov/gmd), and the NILU's Atmospheric Database for Interactive Retrieval (NADIR) at Norsk Institutt for Luftforskning (NILU) (http://www.nilu.no/nadir/). Since June 2007 funding from the Environmental Protection Agency (EPA, Reference Number: 2006-AQ-MS-50) has allowed Valentia Observatory to extend its Ozonesonde launches to a year round weekly programme. The authors want to thank all the above mentioned institutions for their helpful work. We want to thank also the colleagues for launching sondes in Legionowo and Uccle.

Edited by: T. Wagner

\section{References}

August, T., Schlüssel, P., Munro, R., Calbet, X., Oduleye, O., Arriaga, A., Hultberg, T., Hadji-Lazaro, J., Turquety, S., and Clerbaux, C.: ANN ozone retrieval within the operational IASI level 2 processor, in: Proceedings of the 2008 EUMETSAT meteorological satellite conference, Darmstadt, Germany, 8-12 September, 2008.

Boynard, A., Clerbaux, C., Coheur, P.-F., Hurtmans, D., Turquety, S., George, M., Hadji-Lazaro, J., Keim, C., and Mayer-Arnek, J.: Measurements of total and tropospheric ozone from IASI: comparison with correlative satellite and ozonesonde observations, Atmos. Chem. Phys., 9, 6255-6271, 2009, http://www.atmos-chem-phys.net/9/6255/2009/.

Chevallier, F.: Sampled databases of 60-level atmospheric profiles from the ECMWF analyses, EUMETSAT/ECMWF SAF Programme Research Report No. 4, 27 pp., 2001. 
Clerbaux, C., Coheur, P.-F., Hurtmans, D., Barret, B., Carleer, M., Colin, R., Semeniuk, K., McConnell, J. C., Boone, C., and Bernath, P.: Carbon monoxide distribution from the ACEFTS solar occultation measurements, Geophys. Res. Lett., 32, L16S01, doi:10.1029/2005GL022394, 2005.

Clerbaux, C., Hadji-Lazaro, J., Turquety, S., George, M., Coheur, P.-F., Hurtmans, D., Wespes, C., Herbin, H., Blumstein, D., Tournier, B., and Phulpin, T.: The IASI/MetOp I mission: First observations and highlights of its potential contribution to GMES, Space Res. Today, 168, 19-24, 2007.

Clerbaux, C., Boynard, A., Clarisse, L., George, M., Hadji-Lazaro, J., Herbin, H., Hurtmans, D., Pommier, M., Razavi, A., Turquety, S., Wespes, C., and Coheur, P.-F.: Monitoring of atmospheric composition using the thermal infrared IASI/MetOp sounder, Atmos. Chem. Phys., 9, 8307-8339, 2009,

http://www.atmos-chem-phys.net/9/8307/2009/.

Clough, S. A., Shephard, M. W., Mlawer, E. J., Delamere, J. S., Iacono, M. J., Cady-Pereira, K., Boukabara, S., and Brown, P. D.: Atmospheric radiative transfer modeling: a summary of the AER codes, Short Communication, J. Quant. Spectrosc. Radiat. T., 91, 233-244, 2005.

Coheur, P.-F., Barret, B., Turquety, S., Hurtmans, D., Hadji-Lazaro, J., and Clerbaux, C.: Retrieval and characterization of ozone vertical profiles from a thermal infrared nadir sounder, J. Geophys. Res., 110, D24303, doi:10.1029/2005JD005845, 2005.

Cortesi, U., Lambert J. C., De Clercq, C., Bianchini, G., Blumenstock, T., Bracher, A., Castelli, E., Catoire, V., Chance, K. V., De Mazière, M., Demoulin, P., Godin-Beekmann, S., Jones, N., Jucks, K., Keim, C., Kerzenmacher, T., Kuellmann, H., Kuttippurath, J., Iarlori, M., Liu, G. Y., Liu, Y., McDermid, I. S. Y., Meijer, J., Mencaraglia, F., Mikuteit, S., Oelhaf, H., Piccolo, C., Pirre, M., Raspollini, P., Ravegnani, F., Reburn, W. J., Redaelli, G., Remedios, J. J., Sembhi, H., Smale, D., Steck, T., Taddei, A., Varotsos, C., Vigouroux, C., Waterfall, A., Wetzel, G., and Wood, S.: Geophysical validation of MIPAS-ENVISAT operational ozone data, Atmos. Chem. Phys., 7, 4807-4867, 2007, http://www.atmos-chem-phys.net/7/4807/2007/.

Deshler, T., Mercer, J. L., Smit, H. G. J., Stubi, R., Levrat, G., Johnson, B. J., Oltmans, S. J., Kivi, R., Thompson, A. M., Witte, J., Davies, J., Schmidlin, F. J., Brothers, G., and Sasaki, T.: Atmospheric comparison of electrochemical cell ozonesondes from different manufacturers, and with different cathode solution strengths: The Balloon Experiment on Standards for Ozonesondes, J. Geophys. Res., 113, D04307, doi:10.1029/2007JD008975, 2008.

Dupuy, E., Walker, K. A., Kar, J., Boone, C. D., McElroy, C. T., Bernath, P. F., Drummond, J. R., Skelton, R., McLeod, S. D., Hughes, R. C., Nowlan, C. R., Dufour, D. G., Zou, J., Nichitiu, F., Strong, K., Baron, P., Bevilacqua, R. M., Blumenstock, T., Bodeker, G. E., Borsdorff, T., Bourassa, A. E., Bovensmann, H., Boyd, I. S., Bracher, A., Brogniez, C., Burrows, J. P., Catoire, V., Ceccherini, S., Chabrillat, S., Christensen, T., Coffey, M. T., Cortesi, U., Davies, J., DeClercq, C., Degenstein, D. A., De Mazière, M., Demoulin, P., Dodion, J., Firanski, B., Fischer, H., Forbes, G., Froidevaux, L., Fussen, D., Gerard, P., Godin-Beekmann, S., Goutail, F., Granville, J., Griffith, D., Haley, C. S., Hannigan, J. W., Höpfner, M., Jin, J. J., Jones, A., Jones, N. B., Jucks, K., Kagawa, A., Kasai, Y., Kerzenmacher, T. E., Kleinböhl, A., Klekociuk, A. R., Kramer, I., Küllmann,
H., Kuttippurath, J., Kyrölä, E., Lambert, J.-C., Livesey, N. J., Llewellyn, E. J., Lloyd, N. D., Mahieu, E., Manney, G. L., Marshall, B. T., McConnell, J. C., McCormick, M. P., McDermid, I. S., McHugh, M., McLinden, C. A., Mellqvist, J., Mizutani, K., Murayama, Y., Murtagh, D. P., Oelhaf, H., Parrish, A., Petelina, S. V., Piccolo, C., Pommereau, J.-P., Randall, C. E., Robert, C., Roth, C., Schneider, M., Senten, C., Steck, T., Strandberg, A., Strawbridge, K. B., Sussmann, R., Swart, D. P. J., Tarasick, D. W., Taylor, J. R., Tétard, C., Thomason, L. W., Thompson, A. M., Tully, M. B., Urban, J., Vanhellemont, F., Vigouroux, C., von Clarmann, T., von der Gathen, P., von Savigny, C., Waters, J. W., Witte, J. C., Wolff, M., and Zawodny, J. M.: Validation of ozone measurements from the Atmospheric Chemistry Experiment (ACE), Atmos. Chem. Phys., 9, 287-343, 2009,

http://www.atmos-chem-phys.net/9/287/2009/.

Eremenko, M., Dufour, G., Foret, G., Keim, C., Orphal, J., Beekmann, M., Bergametti, G., and Flaud, J.-M.: Tropospheric ozone distributions over Europe during the heat wave in July 2007 observed from infrared nadir spectra recorded by IASI, Geophys. Res. Lett., 35, L18805, doi:10.1029/2008GL034803, 2008.

EUMETSAT: EPS Ground segment, IASI Level2 Product Generation Specification, EPS.SYS.SPE.990013 EUMETSAT Technical Note, online available at: http://www.eumetsat.int/, last access: 2009, 2004.

Fischer, H., Birk, M., Blom, C., Carli, B., Carlotti, M., von Clarmann, T., Delbouille, L., Dudhia, A., Ehhalt, D., Endemann, M., Flaud, J. M., Gessner, R., Kleinert, A., Koopman, R., Langen, J., López-Puertas, M., Mosner, P., Nett, H., Oelhaf, H., Perron, G., Remedios, J., Ridolfi, M., Stiller, G., and Zander, R.: MIPAS: an instrument for atmospheric and climate research, Atmos. Chem. Phys., 8, 2151-2188, 2008, http://www.atmos-chem-phys.net/8/2151/2008/.

Fishman,J. , Ramanathan, V., Crutzen, P. J., and Liu, S. C.: Tropospheric ozone and climate, Nature, 282, 818-820, 1979.

Fishman, J., Wozniak, A. E., and Creilson, J. K.: Global distribution of tropospheric ozone from satellite measurements using the empirically corrected tropospheric ozone residual technique: identification of the regional aspects of air pollution, Atmos. Chem. Phys., 3, 1453-1476, 2003,

http://www.atmos-chem-phys.net/3/1453/2003/.

Flaud, J.-M., Piccolo, C., Carli, B., Perrin, A., Coudert, L. H., Teffo, J.-L., and Brown, L. R.: Molecular line parameters for the MIPAS (Michelson Interferometer for Passive Atmospheric Sounding) experiment, Atmos. Oceanic Opt., 16, 172-182, 2003.

Jones, D. B. A., Bowman, K. W., Horowitz, L. W., Thompson, A. M., Tarasick, D. W., and Witte, J. C.: Estimating the summertime tropospheric ozone distribution over North America through assimilation of observations from the Tropospheric Emission Spectrometer, J. Geophys. Res., 113, D18307, doi:10.1029/2007JD009341, 2008.

Kulawik, S. S., Osterman, G., Jones, D. B. A., and Bowman, K. W.: Calculation of Altitude-Dependent Tikhonov Constraints for TES Nadir Retrievals, IEEE Trans. Geosci. Remote Sensing, 44, 1334-1342, 2006.

Li, D. and Shine, K. P.: A 4-dimensional ozone climatology for UGAMP models, Internal Report No. 35, U.G.A.M.P., 1995.

Liu, X., Chance, K. V., Sioris, C. E., Spurr, R. J. D., Kurosu, T. P., Martin, R. V., and Newchurch, M. J.: Ozone profile and tropospheric ozone retrievals from Global Ozone Monitoring Exper- 
iment: Algorithm description and validation, J. Geophys. Res., 110, D20307, doi:10.1029/2005JD006240, 2005.

Matricardi, M. and Saunders, R. W.: Fast radiative transfer model for simulation of infrared atmospheric sounding Interferometer radiances. Appl. Opt., 38, 5679-5691, 1999.

McPeters, R. D., Labow, G. J., and Logan, J. A.: Ozone climatological profiles for satellite retrieval algorithms, J. Geophys. Res., 112, D05308, doi:10.1029/2005JD006823, 2007.

Nassar, R., Logan, J. A., Worden, H. M., Megretskaia, I. A., Bowman, K. W., Osterman, G. B., Thompson, A. M., Tarasick, D. W., Austin, S., Claude, H., Dubey, M. K., Hocking, W. K., Johnson, B. J., Joseph, E., Merrill, J., Morris, G. A., Newchurch, M., Oltmans, S. J., Posny, F., Schmidlin, F. J., Vömel, H., Whiteman D. N., Witte, J. C.: Validation of Tropospheric Emission Spectrometer (TES) Nadir Ozone Profiles Using Ozonesonde Measurements, J. Geophys. Res., 113, D15S17, doi:10.1029/2007JD008819, 2008.

Nelder, J. A. and Mead, R.: A simplex-method for function minimization, Comput. J., 7, 308-313, 1965.

Oduleye, O., August, T., Calbet, X., Schlüssel, P., Arriaga, A., Hultberg, T., Aulamo, O., Kivi, R., Stiller, B., and Barfus, K.: ASI EOF and ANN Retrieved Total Columnar Amounts Ozone, Compared to Ozone Sonde and Brewer Spectrometer Measurements from the Lindenberg and Sodankylä Validation Campaigns, in: Proceedings of the 2008 EUMETSAT meteorological satellite conference, Darmstadt, Germany, 8-12 September, 2008.

Payan, S., Camy-Peyret, C., Jeseck, P., Hawat, T., Durry, G., and Lefèvre, F.: First direct simultaneous $\mathrm{HCl}$ and $\mathrm{ClONO} 2$ profile measurements in the Artic vortex, Geophys. Res. Letters, 25(14), 2663-2666, 1998.

Phillips, C.: A Technique for the Numerical Solution of Certain Integral Equations of the First Kind, J. Assoc. Comput. Math., 9, 84-97, 1962.

Rodgers, C. D.: Inverse Methods for Atmospheric Sounding: Theory and Practice, World Scientific Publications, Series on Atmospheric, Ocean. Planet. Phys., Vol. 2, Singapore, 2000.

Rothman, L. S. , Jacquemart, D., Barbe, A., Benner, C. D., Birk, M., Brown, L. R., Carleer, M. R., Chackerian Jr., C., Chance, K., Coudert, L. H., Dana, V., Devi, V. M., Flaud, J.-M., Gamache, R. R., Goldman, A., Hartmann, J.-M., Jucks, K.W., Maki, A. G., Mandin, J.-Y., Massie, S. T., Orphal, J., Perrin, A., Rinsland, C. P., Smith, M. A. H., Tennyson, J., Tolchenov, R. N., Toth, R. A., Vander Auwera, J., Varanasi, P., and Wagner, G.: The HITRAN 2004 molecular spectroscopic database, J. Quant. Spectrosc. Rad. T., 96, 139-204, 2005.

Seinfeld, J. H. and Pandis, S. N.: Atmospheric Chemistry and Physics, from Air Pollution to Climate Change, John Wiley \& Sons Inc., Toronto, Canada, 1997.

Smit, H.G.J., Straeter, W., Johnson, B., Oltmans, S., Davies, J., Tarasick, D.W., Hoegger, B., Stubi, R., Schmidlin, F., Northam, T., Thompson, A., Witte, J., Boyd, I., and Posny, F.: Assessment of the performance of ECC-ozonesondes under quasi-flight conditions in the environmental simulation chamber: Insights from the Juelich Ozone Sonde Intercomparison Experiment (JOSIE), J. Geophys Res., 112, D19306, doi:10.1029/2006JD007308, 2007.
Steck, T.: Methods for determining regularization for atmospheric retrieval problems, Appl. Opt., 41, 1788-1797, 2002.

Stiller, G. P. (ed) with contributions from v. Clarmann, T., Dudhia, A., Echle, G., Funke, B., Glatthor, N., Hase, F., Höpfner, M., Kellmann, S., Kemnitzer, H., Kuntz, M., Linden, A., Linder, M., Stiller, G. P., and Zorn, S.: The Karlsruhe Optimized and Precise Radiative Transfer Algorithm (KOPRA), vol. FZKA 6487 of Wissenschaftliche Berichte, Forschungszentrum Karlsruhe, Germany, 2000.

Thompson, A. M., Witte, J. C., McPeters, R. D., Oltmans, S. J., Schmidlin, F. J., Logan, J. A., Fujiwara, M., Kirchhoff, V. W. J. H., Posny, F., Coetzee, G. J. R., Hoegger, B., Kawakami, S., Ogawa, T., Johnson, B. J., Vömel, H., and Labow, G.: Southern Hemisphere Additional Ozonesondes (SHADOZ) 1998-2000 tropical ozone climatology 1. Comparison with Total Ozone Mapping Spectrometer (TOMS) and ground-based measurements, J. Geophys. Res., 108, 8238, doi:10.1029/2001JD000967, 2003.

Tikhonov, A.: On the Solution of Incorrectly Stated Problems and a Method of Regularisation, Dokl. Acad. Nauk SSSR, 151, 501504, 1963.

Tjemkes, S. A., Patterson, T., Rizzi, R., Shephard, M. W., Clough, S. A., Matricardi, M., Haigh, J. D., Höpfner, M., Payan, S., Trotsenko, A., Scott, N., Rayer, P., Taylor, J. P., Clerbaux, C., Strow, L. L., DeSouza-Machado, S., Tobin, D., Knuteson, R.: The ISSWG line-by-line inter-comparison experiment, J. Quant. Spectrosc. Radiat. Transfer, 77, 433-453, doi:10.1016/S00224073(02)00174-7, 2003.

Turquety, S., Hadji-Lazaro, J., and Clerbaux, C.: First satellite ozone distributions retrieved from nadir highresolution infrared spectra, Geophys. Res. Lett., 29, 2198, doi:10.1029/2002GL016431, 2002.

Turquety, S., Hadji-Lazaro, J., Clerbaux, C., Hauglustaine, D. A., Clough, S. A., Cassé, V., Schlüssel, P., and Mégie, G.: Operational trace gas retrieval algorithm for the Infrared Atmospheric Sounding Interferometer, J. Geophys. Res., 109, D21301, doi:10.1029/2004JD004821, 2004.

von Clarmann, T. and Grabowski, U.: Elimination of hidden a priori information from remotely sensed profile data, Atmos. Chem. Phys., 7, 397-408, 2007, http://www.atmos-chem-phys.net/7/397/2007/.

Worden, H. M., Logan, J. A., Worden, J. R., Beer, R., Bowman, K., Clough, S. A., Eldering, A., Fisher, B. M., Gunson, M. R., Herman, R. L., Kulawik, S. S., Lampel, M. C., Luo, M., Megretskaia, I. A., Osterman, G. B., and Shephard, M. W.: Comparisons of Tropospheric Emission Spectrometer (TES) ozone profiles to ozonesondes: Methods and initial results, J. Geophys. Res., 112, D03309, doi:10.1029/2006JD007258, 2007.

Worden, H. M., Bowman, K. W., Eldering, A., and Beer, R.: Satellite measurements of the clear-sky greenhouse effect from tropospheric ozone, Nature Geoscience, 1, 305-308, doi:10.1038/ngeo182, 2008. 